\title{
Conductive Flooring for Hospital Operating Rooms
}

\author{
Thomas H. Boone, Francis L. Hermach, Edgar H. MacArthur, and Rita C. McAuliff
}

(July 9, 1959)

\begin{abstract}
Characteristics and performance of available types of conductive flooring materials were investigated in the laboratory. The study showed that the electrodes and instruments used to measure the floor greatly affected the measured resistance, but that the method specified by the National Fire Protection Association for measuring the electrical resistance reasonably simulated the conditions under which a floor functions in reducing electrostatic hazards. The physical, chemical, and serviceability characteristics of conductive floorings investigated showed results comparable with those of nonconductive flooring of the same type. Consequently, with some limitations, an architect may base his choice of a conductive flooring material on his knowledge of the behavior of similar nonconductive materials.
\end{abstract}

\section{Introduction}

Sparks which can result from the accumulation of static electricity constitute a very real hazard in locations where explosive vapors are present [1]. ${ }^{1}$

The most effective of the several possible means of mitigating this hazard consists in keeping the electrical resistance between all objects in the hazardous locations so low that dangerous voltages are never attained [2]. General quantitative considerations indicate that a resistance of 30 to 50 million ohms between objects is low enough for this purpose, for any rate of separation of charges which can reasonably be expected to be attained by accidental electrostatic processes [1,3]. Most objects normally rest or move upon the floor and therefore can be electrically connected by way of the floor. Flooring of sufficiently low electrical resistance (conductive flooring) is thus of paramount importance in the elimination of electrostatic hazards. At the same time, however, the electrical resistance must be high enough to minimize the possibility of electric shock from faulty electrical wiring or equipment.

The specification and the measurement of the resistance of conductive flooring are greatly complicated by a number of factors, such as the kinds of electrodes and the characteristics of the instrument used. A method recommended by the National Fire Protection Association (NFPA) has had general, but not universal, acceptance for routine measurements of installed floors $[4,5]$. In this method the resistance is measured with a $500-\mathrm{v}$ instrument connected to two similar electrodes placed on the floor. ${ }^{2}$ With these electrodes, which simulate footwear and conductive rubber objects, the specified lower and upper limits of resistance are 25,000 and $1,000,000 \mathrm{ohms}$ (0.025 to $1 \mathrm{meg}$ ).

At present there are quite a few specially compounded proprietary flooring materials which meet

\footnotetext{
Figures in brackets indicate the literature references on page 139.

2 These requirements and recommended methods of testing floors are reproduced in full in appendix $\mathrm{A}$ at the end of this report.
}

these upper and lower limits. However, as is shown in this report, not all of the conductive floors remain within these limits of resistance under all conditions of use.

\section{Scope of Investigation}

A conductive floor must provide a path of prescribed conductance for a reasonable life and should, in addition, possess the physical properties required of an ordinary nonconductive floor. This investigation was planned: (1) To measure by established methods the electrical resistance of each sample of flooring; (2) to determine the effect of all pertinent factors that might affect its resistance, such as wear, aging, moisture, and maintenance; (3) to evaluate the factors that influence the measurement of electrical resistance of conductive flooring, by determining the effect of variations in test conditions upon the measured resistance; (4) to check these results by direct tests in which the flooring serves to reunite electrostatic charges; (5) to compare the significant physical properties of each sample with those of nonconductive floors of the same type. In addition to the tests conducted in the laboratory on samples of flooring, field tests of five different types of conductive floors were made in the Washington area.

Although this investigation was carried out primarily to evaluate conductive floors for hospital operating rooms, many of the results obtained should apply equally well to floors for eliminating electrostatic hazards in other locations such as munitions plants and munitions storage depots.

The authors realize that an additional important property for floors, particularly in hospitals, is that they be made and kept reasonably germ-free. Tests to determine differences in this respect were beyond the scope of this study.

\section{Description of Flooring Samples}

The samples for this study were obtained from domestic suppliers of commercially available con- 
ductive flooring. By request, each manufacturer supplied five similar 18 -in. by 18 -in. floors on plywood panels. The thickness of the floor, bonding technique, and any reinforcement and conductive intercoupling were of the manufacturer's own practice. Thus, each sample received was assumed to be of the type and construction considered by the manufacturer or his trade association as most suitable for conductive flooring.

Preliminary tests of several types of floors with electrodes spaced 1,2, and $3 \mathrm{ft}$ apart, and an analysis of the effect of sample size and shape (see section $5.3)$, showed that the resistance is not greatly affected by electrode spacing. Therefore, convenient 18-in. by 18 -in. samples, which permitted a 1 -ft spacing between electrodes, could be used. The preliminary study showed that the results should be very close to those which would have been obtained had larger samples or even an entire floor been used, with the 3 -ft electrode spacing specified in NFPA 56.

The electrical conductivity of each sample, except the oxychlorides and one make of ceramic tile, depends either completely or partially on the presence of acetylene black (carbon). This is a special form of carbon black produced by the thermal decomposition of acetylene gas under carefully controlled conditions. In the case of the ceramic, linoleum, rubber, and vinyl samples, the carbon black is finely dispersed in the material during manufacture, while in the case of latex, concrete terrazzo, and the setting bed cement for ceramic tile, the carbon black is uniformly dispersed in the dry powder mixes, placed in containers, and shipped for on-the-job composition. Oxychloride floors are made by combining an aqueous solution of magnesium chloride with powdered magnesium oxide. Various fibrous and mineral fillers are mixed with the resulting paste which sets to a hard mass. Marble chips may be added to the mix and the surface ground to produce a terrazzo floor.

Brief descriptions of the composition and installation techniques of each of the conductive floors tested follow:

Ceramic, Sample No. 1: This flooring consisted of an attractive "block random, sprinkle pattern." The design had been made with black conductive tiles,

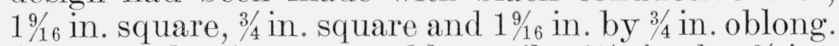
A nonconductive green oblong tile, ${ }^{11} / 32$ in. by $3 / 4$ in., was also inserted. The $1 / 4$-in.-thick tiles were laid in a conductive mortar underbed containing 3 percent acetylene black (carbon). The joints were grouted with nonconductive cement mortar and were approximately $1 / 16$ in. in width.

Ceramic, Sample No. 2: This flooring of brown conductive tile, $1 \frac{1}{16}$ in. square by $1 / 4$ in. thick, had been laid the same as sample No. 1. Samples were also submitted with the tile set in a conductive adhesive using nonconductive cement mortar joints.

Coating, Sample No. 3: This flooring had been made from a mixture of plastics, solvents, and conductive ingredients, the mixture having been applied by spray, brush, or trowel to a thickness of $1 / 16 \mathrm{in}$. It was supplied in black.

Concrete, Sample No. 4: The sample was submitted as representative of conductive concrete terrazzo. Detailed specifications have been published by the National Terrazzo and Mosiac Association for laying carbon black conductive terrazzo floorings for operating suites of hospitals. The sample had been constructed according to these specifications, which included a concrete underbed containing 3 percent carbon black and a terrazzo top surface with 2 percent carbon black. The amount of carbon black was based on the weight of dry cement. The matrix had a dark gray color with stone chips of black and green. These floorings were treated with a recommended penetrating type sealing compound.

Latex, Sample No. 5: This sample was a mixture of a neoprene latex and cement binder with pink, green, and white chips. The material had been troweled $1 / 2$ in. thick and was intended for use over existing or new structurally sound underfloors. As carbon black was used as the conductive medium, only black was available as a matrix color. As in other terrazzodesign floorings, various color combinations can be achieved by use of different colored chips. Approximately 60 percent of the surface area was covered by nonconductive chips. The manufacturer had applied four coats of his recommended sealer.

Linoleum, Sample No. 6: This flooring was black and was available in 6 -ft-wide strips, $1 / 8 \mathrm{in}$. thick. The linoleum had a burlap backing and could be placed over a suitable underfloor by conventional methods of installing linoleum. The manufacturer prescribed brass seam connectors with projecting points for the purpose of electrical intercoupling between sheets. The manufacturer also stated that wax or protective coatings in any form should not be used, and recommended a dry machine brushing to produce a polished appearance.

Oxychloride, Sample No. 7: The conductive terrazzo flooring had been laid $\frac{1}{2}$ in. thick over suitable underfloor. A liquid synthetic resin bonding agent, over which coarse mineral grains were spread, provided the anchoring between the top terrazzo surface and the underfloor. The matrix was green and approximately 50 percent of the surface area was covered with black aed white nonconductive chips.

Oxychloride, Sample No. 8: This sample had been installed in the same manner as sample 7 except that the top $1 / 2-i n$. coating was a plain, dark red, trowel finish.

Oxychloride, Sample No. 9: The conductive terrazzo flooring had been laid $1 / 2 \mathrm{in}$. thick over asphalt felt and wire mesh with a suitable underfloor. The matrix was white and approximately 53 percent of the surface area was covered with black and white nonconductive chips. The surface was coated with a sealer.

Oxychloride, Sample No. 10: The conductive terrazzo flooring had been laid $1 / 2$ in. thick over 2-in.square wire mesh and a suitable underfloor. The matrices of the samples received were red, green, and gray, all with approximately 30 percent of the surface area covered with black and white nonconductive chips. 
Oxychloride, Sample No. 11: The conductive terrazzo flooring had been laid $1 / 2 \mathrm{in}$. thick over suitable underfloor. The matrix of this sample was green with approximately 65 percent of the surface area covered with black, green, and white nonconductive chips.

Oxychloride, Sample No. 12: The plain, trowelfinished, conductive flooring had been applied $1 / 2 \mathrm{in}$. thick over a suitable bonding agent and a suitable underfloor. The sample received was red, but other colors are also available. This so-called cupric oxychloride material differed from the other oxychlorides in that it contained finely divided copper powder $(5-10 \%$ by weight of dry mix), which was claimed to impart a number of desirable characteristics. The manufacturer stated that the flooring should not be waxed, and recommended the use of a special sealer.

Rubber, Sample No. 13: This flooring consisted of rubber, homogeneously compounded with acetylene carbon black. The material was black, 1/8 in. thick, with a cotton fabric backing. Adhesive was used to fasten the sheets to a suitable underfloor and intercouplings similar to those used with linoleum (sample no. 6) can be used to connect the sheets of rubber electrically.

Vinyl, Sample No. 14: This flooring consisted of 9 -in. by 9 -in. polyvinyl chloride-based tiles, $1 / 8$ in. thick, with a black conductive field and a white and green marbleized design. Installation was effected with a special underlayment felt which carried its own pressure-sensitive adhesive on both sides, thus serving to bond the felt to the underfloor and the tile to the felt. Copper foil, $1 / 2$ in. wide, was placed on the felt to provide an electrical intercoupling between tiles.

Vinyl, Sample No. 15: This flooring consisted of 9 -in. by 9 -in. polyvinyl chloride-based tiles, $3 / 16$ in. thick, with a molded terrazzo design of either a white or gray field with a black "chiplike" effect. Installation was by troweling adhesive onto a suitable underfloor and placing 1-in. copper foil on the adhesive to provide an electrical intercoupling between tiles.

\section{Factors Influencing the Electrical Resistance}

The changes of electrical resistance of the sample floorings when subjected to a practical range of environmental conditions were determined. Based on previous knowledge of the behavior of some similar types of floorings, the following were selected as the most important factors: aging, moisture, and maintenance procedures.

All of the resistance measurements were made in accordance with section 6-2 of NFPA method No. 56 (see app. A) except for reduced spacing of electrodes. This established test method provided a good basis for comparison of these floors, and, as shown in subsequent sections, proved to be suitable and realistic.

\subsection{Age}

In order to determine what changes may occur in the electrical resistance of conductive flooring as it ages, resistance measurements were taken over a period of 30 months for all samples except sample 4, which was received much later than the others. During this time the samples were exposed to $50 \pm 2$ percent relative humidity (rh) and a temperature of $22^{\circ} \pm 1^{\circ} \mathrm{C}$. At intervals four measurements were made at four different positions on each panel with the electrodes $10 \mathrm{in}$. apart. A template was used to assure that the electrodes were always placed on the same areas of each sample. The graphs (fig. 1) illustrate the electrical resistance of each sample as a function of time. As indicated in figure 1, aging did not significantly affect the resistance of the floors except for some oxychloride samples.

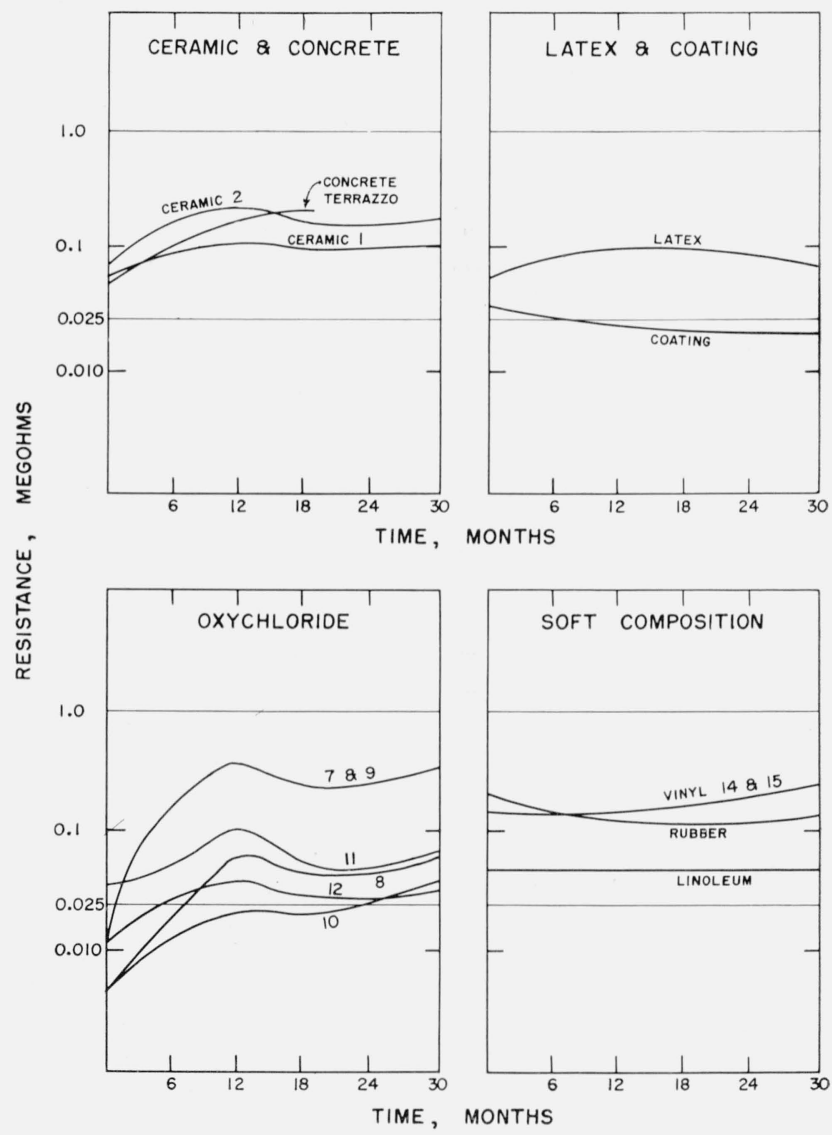

FIGURE 1. Effect of aging on electrical resistance as measured by the NFPA method.

Ambient temperature $22^{\circ} \pm 1^{\circ} \mathrm{C}$, relative humidity 50 percent.

\subsection{Humidity}

Although the relative humidity in some hospital operating suites is controlled automatically by air conditioning equipment and thus can be maintained at any desired level, such equipment is still generally lacking, and most conductive floors are therefore 
exposed to wide variations in relative humidity. Tests were conducted to determine the effect of extremes of relative humidity on the electrical resistance of the flooring samples. The samples were exposed to an atmosphere of $10 \pm 1$ percent rh at $38^{\circ} \pm 1^{\circ} \mathrm{C}$ for 3 weeks and to an atmosphere of $80 \pm 1$ percent rh at $27^{\circ} \pm 1^{\circ} \mathrm{C}$ for 1 week. In the interval between the two tests they were stored at $22^{\circ} \pm 1^{\circ} \mathrm{C}$ and 50-percent rh for 2 weeks. The electrical resistance was measured at the beginning and end of each of the two tests and for several days after the conclusion of each test. The results of these tests are shown by the solid lines in figure 2. As is evident from these graphs, only the oxychlorides were materially affected. It is evident that the electrical resistance of oxychloride flooring is dependent on its moisture content. As shown by the graphs, exposure of the oxychloride samples to 80 -percent rh caused their resistance to fall below the $25,000-\mathrm{ohm}$ minimum and exposure to 10-percent rh caused their resistance to go above the 1 -meg maximum.

The effect of humidity on electrical resistance was pointed up secondarily in an investigation whose
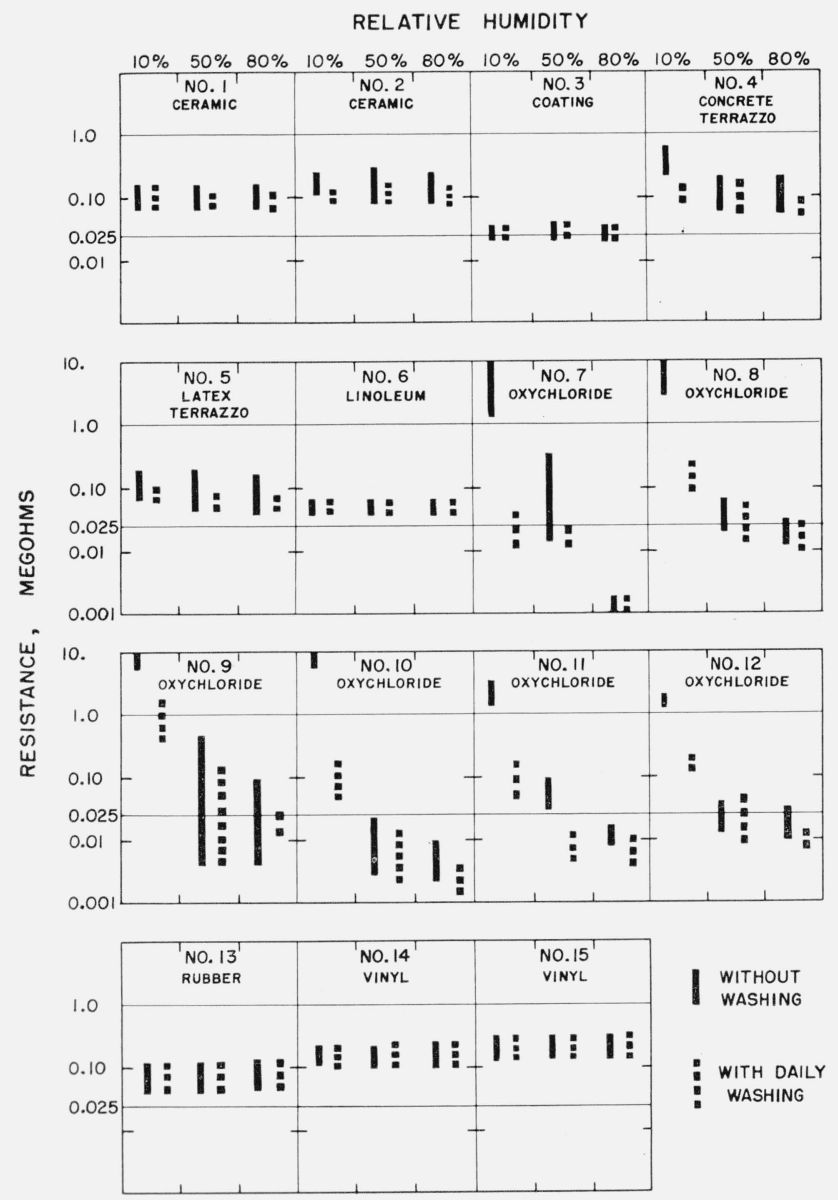

Figure 2. Effect of ambient relative humidity and daily washing on electrical resistance as measured by the NFPA method. primary purpose was the study of the effect of alkali or lime content on the electrical resistance of various cement mixes. A few scattered measurements, made a number of years ago, had indicated that concretes made with high-alkali cements apparently had lower electrical resistance than those with low-alkali or high-lime content. Because conduction in concrete is electrolytic, this seemed to warrant further investigation, since ordinary concrete is not far above the present specification limit at moderate humidities. The results (table 1) verified that high alkali concrete does have somewhat lower resistance than the other types, but the difference is not marked and may be due to unknown factors. Table 1 also illustrates the effect of humidity on the electrical resistance of ordinary concrete (without carbon black).

TABLE 1. Electrical resistance of concrete specimens

\begin{tabular}{|c|c|c|c|c|}
\hline \multirow{2}{*}{ NBS No. } & \multirow{2}{*}{ Alkali } & \multirow{2}{*}{$\mathrm{CaO}$} & \multicolumn{2}{|c|}{ Resistance } \\
\hline & & & At $15 \%$ rh & At $50 \%$ rh \\
\hline $\begin{array}{ll}1 & \mathrm{HA} \\
2 & \mathrm{HA} \\
3 & \mathrm{HA} \\
1 & \mathrm{LA} \\
2 & \mathrm{LA} \\
\end{array}$ & $\begin{array}{l}\% \\
0.89 \\
.91 \\
.91 \\
.13 \\
.08\end{array}$ & $\%$ & $\begin{array}{r}m e g \\
70 \\
50 \\
70 \\
400 \\
150\end{array}$ & $\begin{array}{r}m e g \\
8 \\
11 \\
9 \\
60 \\
30\end{array}$ \\
\hline $\begin{array}{l}3 \mathrm{LA} \\
1 \mathrm{HAC} \\
2 \mathrm{H} \mathrm{H} \\
3 \\
3 \mathrm{HC}\end{array}$ & .30 & $\begin{array}{l}65.0 \\
63.5 \\
63.3\end{array}$ & $\begin{array}{r}400 \\
440 \\
80 \\
90\end{array}$ & $\begin{array}{l}50 \\
80 \\
20 \\
15\end{array}$ \\
\hline
\end{tabular}

NOTE: $\mathrm{HA}=$ High alkali cement; $\mathrm{LA}=$ Low alkali cement; $\mathrm{HC}=$ High lime cement. The samples were 1 - by 1 - by 11 -in. concrete bars made with three different types of cement, each from a different supplier. All were of 1:1:2 mix (cement, fine, and coarse aggregate, respectively) with a cement-water ratio of (cement, fine, and coarse aggregate, respectively) with a cement-water ratio of about $36 \%$. The samples were damp-cured and were then placed in a controlled
humidity cabinet, first at $15 \% \mathrm{rh}$ and then at $50 \% \mathrm{rh}$, at room temperature. humidity cabinet, first at $15 \% \mathrm{rh}$ and then at $50 \% \mathrm{rh}$, at room temperature.
The resistance of each was measured periodically with a 500-v d-c instrument between two resilient electrodes, one at each end of the same surface of the bar.

\subsection{Surface Moisture}

Since the floors of a hospital operating room are naturally kept as clean as possible, tests were conducted to determine the effect of routine maintenance (i.e., water mopping) on the electrical resistance of the samples. The samples were mopped at 9:00 a.m. daily for 1 week with a rubber sponge saturated with water, and any excess water was allowed to remain. The electrical resistance was measured daily at 1:00 p.m. Three series of such tests were run, one at $10 \pm 1$-percent $\mathrm{rh}\left(38^{\circ} \mathrm{C}\right)$, one at $50 \pm 2$-percent $\mathrm{rh}\left(22^{\circ} \mathrm{C}\right)$, and the third at 80 \pm 1 -percent $\mathrm{rh}\left(27^{\circ} \mathrm{C}\right)$. The effect of these tests on the electrical resistance of the specimens is indicated by the dashed lines in figure 2. Again, the oxychlorides were the only samples that were materially affected, their resistance falling below the minimum permissible limit in all cases except in the test at 10 -percent $\mathrm{rh}$.

\subsection{Service}

In order to determine the degree of correlation between laboratory tests and tests of some conductive flooring in actual service, field tests were made 
of floors in several hospitals in the Washington area. The results are shown in table 2 . They indicate reasonably good correlation between the measured resistances of the samples and the installed floors under roughly comparable conditions.

TABLE 2. Comparison of field and laboratory tests

\begin{tabular}{|c|c|c|c|}
\hline \multirow{2}{*}{ Type of floor } & \multirow{2}{*}{$\begin{array}{c}\text { Similar to } \\
\text { sample No. }\end{array}$} & \multicolumn{2}{|c|}{ Range of electrical resistance } \\
\hline & & Field & $\begin{array}{c}\text { Laboratory (rh 10\% } \\
\text { to } 80 \%)\end{array}$ \\
\hline $\begin{array}{l}\text { Ceramic } \\
\text { Concrete terrazzo } \\
\text { Concrete terrazzo } \\
\text { Linoleum } \\
\text { Oxychloride } \\
\text { Vinyl }\end{array}$ & $\begin{array}{r}1 \\
4 \\
4 \\
7 \\
9 \\
15\end{array}$ & $\begin{array}{l}\quad m e g \\
0.085 \text { to } 0.20 \\
.12 \text { to } 1.5 \\
a .80 \text { to } 9.0 \\
.025 \text { to } .045 \\
b 4.0 \text { to } 10 \text { or more } \\
.048 \text { to } .068\end{array}$ & $\begin{array}{l}m e g \\
0.050 \text { to } 0.13 \\
.050 \text { to } .33 \\
.050 \text { to } .33 \\
.037 \text { to } .055 \\
.012 \text { to } 10 \text { or more } \\
.17 \text { to } .26\end{array}$ \\
\hline
\end{tabular}

a The installation method now specified by the National Terrazzo and Mosaic Association would probably eliminate this type of failure.

$b$ This floor had been out of service for about three months and had not been washed regularly.

\section{Factors Influencing the Determination of Resistance}

The established method given in NFPA No. 56 (see appendix A) for measuring the electrical resistance of installed floors represents a series of compromises among several conflicting requirements. These have been necessary because, unlike metallic conductors, the resistance of the usual conductive flooring material depends upon how it is measured. It is greatly dependent upon such factors as voltage gradient, type and shape of electrode, and time and frequency of applied voltage. The large number of floors submitted in this program made it possible to evaluate these factors on a much better basis than heretofore.

The fundamental principle used in these studies was that a material whose properties depend upon the conditions of measurement should be measured by methods which simulate as closely as practicable the conditions under which the material is expected to function. The tests were intended to evaluate this similarity for each of the effects which prior experience had indicated were significant.

\subsection{Applied Voltage}

One of the most important of these effects is that of applied voltage. For most conductive flooring materials conduction is either by the migration of ions (electrolytic) or by complex chains of particles of carbon in a nonconducting matrix. In either mechanism it would be expected that the magnitude of the applied voltage would affect the measured resistance. To determine this a Wheatstone bridge ${ }^{3}$ was used to apply a d-c voltage to each sample and

${ }^{3}$ A commercial megohm bridge with an electronic detector was modified for these tests to measure resistance down to $0.001 \mathrm{meg}(1,000 \mathrm{ohms})$ and to provide an adjustable bridge voltage. It had an effective internal resistance of $50,000 \mathrm{ohms}$, to limit the current for the protection of the operator and to avoid overheating low-resistance samples. This affects the voltage applied to the sample, as shown in section 5.5 In these tests the voltage actually applied to the sample was in section 5.5 to measure the corresponding resistance. The voltage was increased in steps of $50 \mathrm{v}$ to the maximum output voltage obtainable (limit $500 \mathrm{v}$.).

The results for typical flooring materials are given in figure 3. They show that for most materials the resistance is approximately an exponential function of the applied voltage, described by an equation of the form $R=k V^{n}$. The exponent, $n$, ranged from 0 to -2 .

Experiments have shown that a minimum voltage of about $400 \mathrm{v}$ is required for an electrostatic spark in air at atmospheric pressure [2]. Thus the principle just mentioned indicates that a voltage near this should be used in evaluating floors for locations such as hospital operating rooms, in which ignition of flammable gases by sparks is the principal hazard. Such floors should not be measured by ordinary ohmmeters which apply only a few volts to the sample. Fortunately 500-v insulation-measuring instruments (direct or ratio ohmmeters) are readily available.

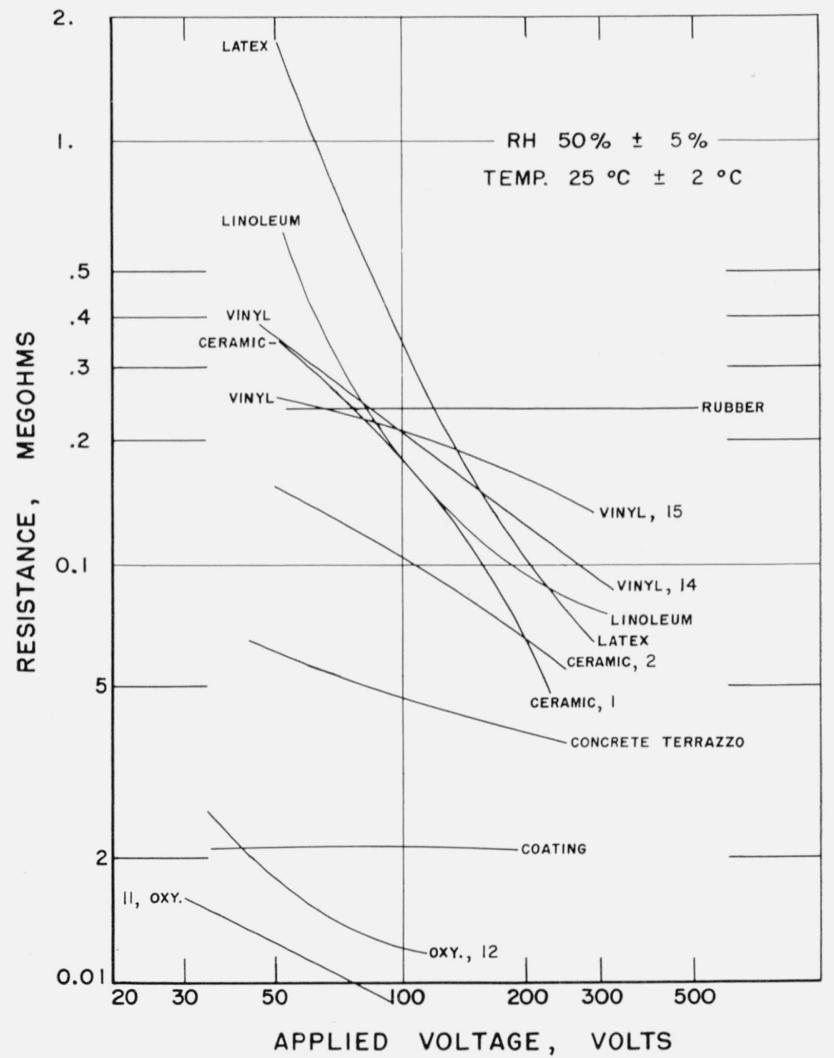

FIGURE 3. Effect of applied voltage on resistance as measured by the NFPA method.

\subsection{Time}

The conventional method of measuring the electrical resistance of an installed floor, for example the method specified in NFPA No. 56, is, in effect, a "steady state" method in which the resistance is measured several seconds after the direct voltage is applied. In practice, static electricity is "generated" (charges are separated) by motions, such as 
removing a sheet from a table or getting up from a chair, the durations of which are comparatively short, generally in the range from 0.01 to 1 sec [1]. Thus it is the short-time resistance or "surge resistance" of a floor which determines the rate at which the separated charges reunite. For some types of polarization of flooring materials this initial resistance may be less than the steady-state value.

The initial and steady-state resistances of a number of types of flooring materials were evaluated with a cathode ray oscillograph in the circuit shown in figure 4. The oscillograph was connected across a resistor of low inductance to record the current through the sample when the switch, S, was closed. The oscillograph was triggered by the same switch and operated in the single sweep mode, with a sweep time of about 30 msec. After 3 sec the current was read from the milliammeter and the sweep was again repeated without interrupting the current. The ratio of the initial resistance to the steady-state resistance was computed from the initial deflection of the oscillograph (generally observed about 1 msec after the switch was closed), and the deflection at 3 sec.

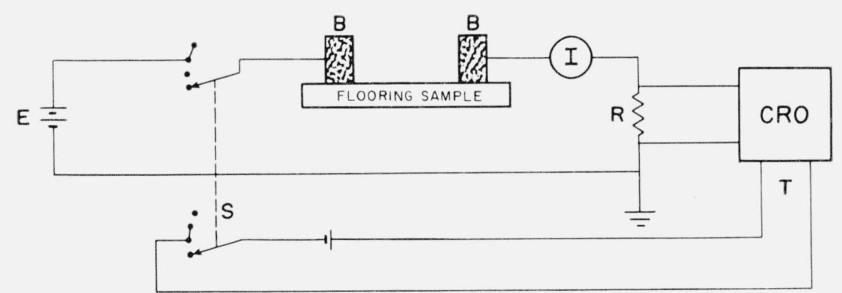

FI@URE 4. Laboratory circuit for measuring initial and steadystate resistance.

B, NFPA standard electrode; R, a-c resistor; CRO, cathode-ray oscilloscope and camera, connected to $\mathrm{R}$ with coaxial cable, shield at ground potential; T, leads to sweep trigger circuit of CRO; I, milliammeter.

Tests were made at battery voltages of 150 and $400 \mathrm{v}$, at an ambient temperature of about $25^{\circ} \mathrm{C}$, and a relative humidity of 50 to 60 percent. The results are shown in table 3 . In most cases the observed difference between the initial and steadystate deflections was small. On this basis it is evident that the 3 -sec values of resistance as presently specified for routine tests are not significantly in error and that the fractional changes in resistance for shorter times are not unduly large for the flooring samples tested.

TABLE 3. Ratio of initial resistance, $R_{i}$, to steady-state resistance, $R_{f}$, of flooring samples (standard electrodes, relative humidity $50-60 \%$ )

\begin{tabular}{|c|c|c|c|}
\hline Sample & Type & $R_{f}$ & $R_{i} / R_{f}$ \\
\hline 1 & Ceramic & meg & 0.8 \\
\hline $\begin{array}{l}1 \\
2\end{array}$ & Ceramic... & $\begin{array}{r}0.10 \\
.08\end{array}$ & $\begin{array}{r}0.8 \\
.7\end{array}$ \\
\hline 3 & Coating & .04 & .9 \\
\hline 5 & Latex....... & .08 & . \\
\hline 6 & Linoleum & .11 & 1.0 \\
\hline 11 & Oxychloride & .04 & 0.8 \\
\hline 13 & Rubber & .26 & .9 \\
\hline 14 & Vinyl & .23 & 8 \\
\hline 15 & Vinyl... & .41 & .8 \\
\hline
\end{tabular}

\subsection{Contact Resistance}

Experiments have shown that most flooring materials exhibit surprisingly large "contact resistances" at the interfaces between the material and the electrodes which are used to measure the resistance. Because of this the two-terminal method of testing installed flooring (using two electrodes) does not measure the true internal or volume resistance of the flooring material. When necessary, the contact and volume resistivities are best determined by making four-terminal measurements in which two "current" electrodes are used to carry current to the sample under test, with two separate "potential" electrodes between them, connected to a voltmeter whose resistance is much greater than the resistance of the sample. If the electrodes are placed on a rectangular sample as shown in figure 5 , the potential electrodes do not disturb the potential gradient in the sample. Then, if the resistance between the current electrodes, the applied voltage, and the voltage between the potential electrodes are measured simultaneously, the average contact resistivity and the internal resistivity can be computed, as shown in appendix B.

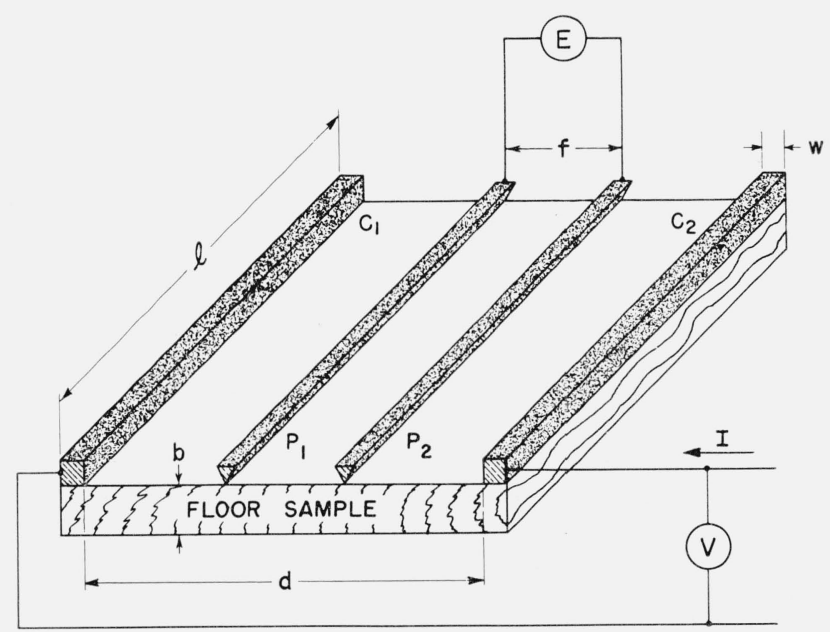

Figure 5. Four-terminal method of measuring contact and volume resistance.

Several typical samples ${ }^{4}$ were measured by this method with the 500-v megohm bridge. The direct voltage from the bridge was applied to two barshaped current electrodes, $1 \frac{1}{2}$ in. wide and 18 in. long (faced with rubber and covered with foil like NFPA electrodes), with the potential electrodes between them. An electronic voltmeter with an input resistance of $10^{12} \mathrm{ohms}$ was used to measure $E$. The results are shown in table 4 . From this table it is apparent that for each of these materials the contact resistivity with this type of electrode is much greater than the internal resistivity.

It has been argued that the test of an installed floor should be a measurement of the true internal

${ }^{4}$ Samples which had an embedded wire mesh could not of course be evaluated by this method. 
TABLE 4. Contact and internal resistivities

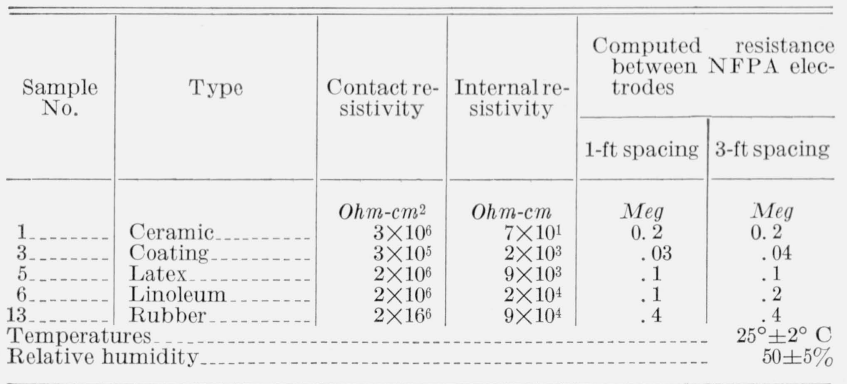

resistivity of the material and should be made by reducing as far as possible the contact resistivity, for instance by using conductive jelly under the electrodes. However, objects in the operating room must contact the floor, and the principle previously outlined requires that the test electrodes should properly simulate such contacts. In addition, fourterminal measurements show that it is not possible to eliminate contact resistance completely even with wetted electrodes.

The separation of contact and internal resistivity makes it possible to calculate the resistance to be expected for many different configurations of electrodes. In particular, the resistance between two NFPA electrodes on a large floor can easily be determined, as shown in appendix C. The values calculated in this way for several of these flooring samples are given in the last two columns of table 4 . These show that the measured resistance is not appreciably affected by the electrode spacing because of the high contact resistivity which is independent of spacing and because the internal resistance of the material between the electrodes is a logarithmic rather than a linear function of the ratio of the electrode diameter to the electrode spacing. Increasing the spacing from 1 to $3 \mathrm{ft}$ increases the internal resistance by less than 50 percent (and does not affect the contact resistance). In addition, the limited area of the 18 by 18 -in. samples, which restricts the lines of current flow, increases the internal resistance and somewhat offsets the effect of the reduced electrode spacing.

The computed results agree reasonably well with the values measured for the same samples with NFPA electrodes at approximately the same voltage and ambient relative humidity. The results of these measurements are given in the next section.

\subsection{Electrodes}

Because of the high contact resistivity it would be expected that the kind and size of electrodes would have marked effects on the measured resistance of conductive floors. From the principle already given, the electrodes should simulate the contacting objects. In an operating room, such objects are of two general types: (a) Soft, resilient materials, such as conductive-rubber shoe soles and heels and conductiverubber casters and leg tips on furniture; and (b) hard objects such as metal leg tips and gliders. The force on these objects can be expected to vary over a fairly wide range, from perhaps a few pounds (light pail) to several hundred pounds (operating table). Thus no one electrode can be expected to simulate all of these objects.

To evaluate these effects, tests were made of typical materials with several different electrodes and with added weights on each electrode. All measurements were made with the $500-\mathrm{v}$ bridge and at an ambient relative humidity of 30 to 50 percent. Five readings, with the electrodes at different locations, were made on each sample. The average results are given in table 5, along with a key to the types of electrodes used.

TABLE 5. Results of tests with different electrodes

\begin{tabular}{|c|c|c|c|c|c|c|c|c|}
\hline \multirow{2}{*}{$\begin{array}{c}\text { Sample } \\
\text { No. }\end{array}$} & \multirow{2}{*}{ Type } & \multicolumn{7}{|c|}{ Resistance in meg (see key below) } \\
\hline & & $\mathrm{S}$ & SW & $\mathrm{H}$ & $\mathrm{HW}$ & $\mathrm{C}$ & $\mathrm{CS}$ & $\mathrm{B}$ \\
\hline 1 & Ceramic & 0.055 & 0.037 & 0.29 & 0.24 & 0.33 & 0.14 & 6.5 \\
\hline 2 & Ceramic & .11 & .060 & 1.4 & .80 & .65 & .34 & 0.85 \\
\hline 4 & Concrete ${ }^{\mathrm{a}}$ & .026 & & 0.28 & & .30 & .38 & .85 \\
\hline 5 & Latex .... & .051 & .040 & .16 & 080 & .22 & .11 & \\
\hline 6 & Linoleum ........ & .051 & .049 & .080 & .080 & 17 & 10 & \\
\hline 7 & Oxychloride... & .022 & .019 & .080 & .060 & 2. 0 & 1. 0 & \\
\hline 12 & Oxychloride & .023 & .019 & .11 & .070 & 0.25 & 0.65 & \\
\hline 13 & Rubber & .24 & .23 & .36 & .33 & & .41 & \\
\hline 15 & Vinyl ... & .16 & .11 & .37 & .22 & b 1.0 & 1. 7 & 1.0 \\
\hline
\end{tabular}

Key

\begin{tabular}{c|c}
\multicolumn{1}{c|}{ Symbol } & \multicolumn{1}{c}{ Type of electrode } \\
\cline { 1 - 2 } S._. & $\begin{array}{l}\text { Two 5-1b, 2.5-in. diam electrodes, with flat but resilient contact } \\
\text { face on each, conforming to NF A No. 56. } \\
\text { Same as S with 50-lb additional weight on each electrode. } \\
\text { Two 5-lb electrodes with flat steel contact faces, 1-in. diam, having } \\
\text { rounded edges. }\end{array}$ \\
$\begin{array}{l}\text { Same as H with 50-lb additional weight on each electrode. } \\
\text { Two conductive casters, 3-in. diam, 3/4-in. tread. Weight of each } \\
\text { about 1 lb with 5-lb additional weight on each caster. } \\
\text { One type "C"' and one type "S" electrode. } \\
\text { Two 5-lb electrodes, each having three-legged contacts of 1/8-in. by } \\
\text { 1/8-in. brass rods, having flat surfaces and sharp edges. }\end{array}$
\end{tabular}

a Sample tested shortly after receipt, before aging.

b Moderate variations. Some additional readings up to $100 \mathrm{meg}$.

The results show that for all materials the resistance measured with the resilient NFPA electrodes is not appreciably affected by large changes in force, so that these electrodes, which weigh only $5 \mathrm{lb}$ and are reasonably portable, can simulate the much heavier objects likely to be encountered in operating rooms. For resilient floors (such as vinyl tile, rubber, linoleum, and the coating with the wood backing) the results with the hard electrodes, which simulate metal leg tips and gliders, are not appreciably higher than with the NFPA electrodes. However, with hard-surfaced materials (oxychloride, concrete terrazzo, and ceramic tile) the actual contact area was much less than with the resilient electrodes, and the measured resistances were greater by factors as large as 10 or more (and in one case by a factor of 100). In general, the scattering in the 5 readings of resistance with each electrode (only the average values are shown in the table) was very much greater with the hard than with the resilient electrodes. The conductive casters, which have a small contact area, showed marked scattering in readings of resistance 
on some samples. The differences between results with two standard electrodes and those with two casters were less marked for resilient flooring (except for vinyl tile) than for hard-surfaced materials. (Field tests of a conductive vinyl tile floor of the same manufacture gave nearly equal results with casters and standard electrodes.) The special 3legged electrodes have been suggested for simulating high-pressure contacts. The resistances were in general comparable with or somewhat higher than those with the 1-in. hard electrodes.

Thus the resilient electrodes simulate well one type of floor contact and give much more uniform and reproducible results than hard-surfaced electrodes. However, when such resilient electrodes are specified, the upper limit of resistance for an installed floor must contain a large factor of safety to allow for hard-surfaced objects which are also widely used. This factor depends upon the resiliency of the floor, so that apparently the specified upper limit with a resilient floor such as conductive rubber or linoleum could safely be 10 times as high, when measured with these electrodes, than the limit for a hard floor such as oxychloride or concrete terrazzo.

\subsection{Frequency}

The lower limit of resistance specified in NFPA No. 56 for conductive floors is intended to provide some (but not complete) protection from electric shock. Alternating current $(120 \mathrm{v}, 60 \mathrm{cps})$ is almost universally used in this country for electrical utilization circuits. Because of this it would appear that the resistance of the floor should be measured at this voltage and frequency to determine compliance with the lower limit. For convenience, however, the same d-c instrument is normally used for both upper and lower limit tests. The instrument commonly specified has an open circuit voltage of $500 \mathrm{v}$. However, the actual voltage that it impresses on the floor under test depends upon the resistance of the floor and the internal resistance of the instrument, as shown in figure 6 . From this figure it is apparent that a 500-v instrument having an internal resistance of almost $0.1 \mathrm{meg}$ will impress about $100 \mathrm{v}$ on a sample near the NFPA lower limit of $25,000 \mathrm{ohms}$ (0.025 meg).

Measurements of several flooring samples were made at $100 \mathrm{v}$, with alternating and direct current, and with a typical 500-v ohmmeter which has an internal resistance of $0.1 \mathrm{meg}$. All measurements were made with the standard resilient electrodes at the same location on each sample, and at an ambient relative humidity of about 40 percent. The results given in table 6 shown no really significant differences between the a-c and d-c measurements of a given sample at $100 \mathrm{v}$. They also show that for samples near the lower limit of $0.025 \mathrm{meg}$ the ohmmeter value agreed reasonably well with others. For samples of higher resistances the ohmmeter impressed more than $100 \mathrm{v}$ on the sample and the measured resistance was, in general, less, as would be expected from the observation that resistance is an inverse function of the voltage, as shown in sec-
TABLE 6. Ac-dc comparison tests

\begin{tabular}{|c|c|c|c|c|}
\hline \multirow{2}{*}{$\begin{array}{l}\text { Sample } \\
\text { No. }\end{array}$} & \multirow{2}{*}{ Type } & \multicolumn{3}{|c|}{ Resistance in meg } \\
\hline & & $\begin{array}{l}\text { At } 100 \mathrm{v} \\
60 \mathrm{cps}, \mathrm{ac}\end{array}$ & At $\underset{d c}{100 \mathrm{~V}}$ & $\begin{array}{c}\text { With } \\
\text { ohmmeter }\end{array}$ \\
\hline 1 & Ceramic_. & 0.20 & 0.23 & 0.075 \\
\hline 2 & Ceramic . & .31 & .34 & .10 \\
\hline 4 & Concrete.. & .009 & .024 & .015 \\
\hline 5 & Latex & .21 & .25 & .075 \\
\hline 6 & Linoleum_ & .055 & .057 & .050 \\
\hline 8 & Oxychloride_. & .042 & .038 & .030 \\
\hline 11 & Oxychloride... & .012 & .007 & .010 \\
\hline 12 & Oxychloride & .063 & .040 & .040 \\
\hline 13 & Rubber........ & .21 & .23 & .21 \\
\hline 15 & Vinyl & .60 & .78 & .20 \\
\hline
\end{tabular}

tion 5.1. The 500-v instrument specified in NFPA No. 56 (internal resistance 50,000 to $200,000 \mathrm{ohms})^{5}$ thus can be expected to give results which are reasonably close to those obtained with the somewhat more complex instruments required for a-c measurements, and make it unnecessary to specify two different instruments for measuring installed floors. However, as figure 6 shows, the range of internal resistance specified in NFPA No. 56 could be greatly narrowed. A short circuit current of $5 \pm 0.5$ ma corresponding to a nominal internal resistance of $100,000 \mathrm{ohms}$ is suggested.

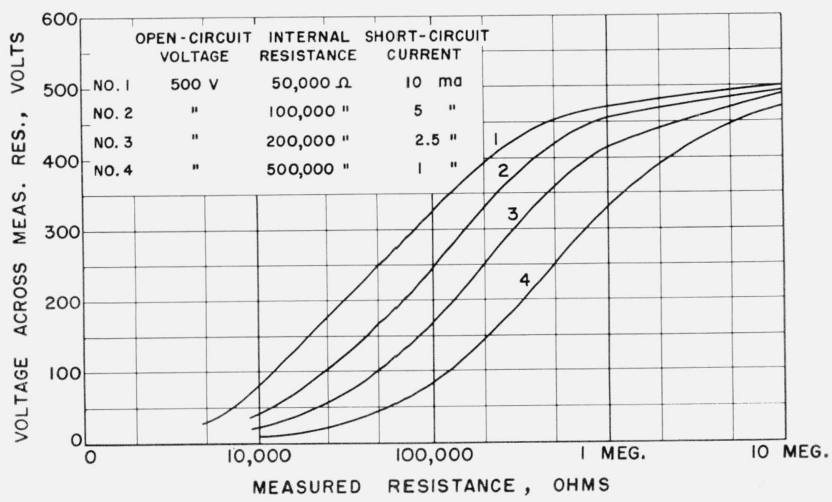

FIGURE 6. Output voltage of ohmmeters as a function of measured resistance.

Characteristics of ohmmeters shown in block on graph.

\subsection{Instruments}

A number of different instruments are commercially available for measuring the resistance of conductive floors. Instruments fall into three general classes: (a) simple ohmmeters; (b) ratio ohmmeters; and (c) Wheatstone bridges [6].

A simple d-c ohmmeter consists of a battery, milliammeter, and a resistor, $R$, all in series with the unknown resistor, $X$, to be measured. The current through the milliammeter is adjusted (by shunting the milliammeter or adjusting $R)^{6}$ to give full scale deflection of the instrument, which is marked zero on the scale. The current through the instrument is then a function of $X$ and the scale is marked

5 The internal resistance can usually be computed as the quotient of the open 5 The internal resistance can usually be computed as the quotient of the
circuit voltage divided by the short circuit current of the instrument.

$6 \mathrm{It}$ is much more desirable to shunt the milliammeter, since the calibration ${ }^{6}$ It is much
depends on $R$. 
accordingly. Such ohmmeters with 1.5- or 3-v batteries are commonly used in radio or television service instruments. As indicated in section 5.1, these voltages are far too low for meaningful tests of conductive flooring. However, at least one manufacturer has incorporated a vibrator-transformer power supply operated from a dry cell to produce a $500-\mathrm{v}$ conductive-flooring tester.

The moving element in a ratio-type ohmmeter contains a permanent magnet and two rotatable coils fixed at right angles to each other, one of which functions as in the simple ohmmeter while the other carries a current proportional to the applied voltage. With no springs, the coils then take up a position which is a function of the ratio of the voltage to the current, and the scale is laid off in ohms or megohms. The reading is then desirably independent of the voltage, and a zero setting is not necessary. Most ratio ohmmeters also contain handcranked generators to produce the desired voltage.

Wheatstone bridges with electronic detectors have been used occasionally, but are best suited for laboratory work, since a balance must be made before each reading. They are generally capable of greater accuracy and flexibility than ohmmeters.

Table 7 shows the general characteristics of commercially available instruments which are suitable for testing conductive flooring. In accordance with NFPA No. 56, such instruments must have an open circuit voltage of $500 \mathrm{v}$, a short circuit current of 2.5 to $10 \mathrm{ma}$, and should have a range of at least 0.01 to 2 meg. Unfortunately, many models of $500-\mathrm{V}$ insulation testers have a higher internal resistance and resistance range than this. Only moderate accuracy is required in field tests of conductive flooring because of the large variations inherent in most materials. An accuracy of 20 percent of the measured resistance in the range 0.025 to $1 \mathrm{meg}$ should be adequate. It can be shown that, because the scale of an ohmmeter is necessarily nonlinear, the markings on the scale must then be accurate to 2 percent of the full-scale length, and the resistors and

TABLE 7. Characteristics of typical instruments for measuring resistance of conductive floors

\begin{tabular}{|c|c|c|c|c|c|c|c|}
\hline \multirow{2}{*}{ Туре } & \multirow{2}{*}{$\begin{array}{l}\text { Energy } \\
\text { source }\end{array}$} & \multirow{2}{*}{$\begin{array}{c}\text { Open- } \\
\text { circuit } \\
\text { voltage }\end{array}$} & \multirow{2}{*}{$\begin{array}{l}\text { Short- } \\
\text { circuit } \\
\text { current }\end{array}$} & \multirow{2}{*}{$\begin{array}{c}\text { Inter- } \\
\text { nal re- } \\
\text { sistance }\end{array}$} & \multicolumn{2}{|c|}{ Range a } & \multirow{2}{*}{$\begin{array}{l}\text { Ap- } \\
\text { proxi- } \\
\text { mate } \\
\text { mid- } \\
\text { scale } \\
\text { readin }\end{array}$} \\
\hline & & & & & Low & High & \\
\hline Ratio ohm- & Hanc & $\stackrel{v}{0-500}$ & $\begin{array}{l}m a \\
3.5\end{array}$ & \begin{tabular}{c|} 
meg \\
0.14
\end{tabular} & $\begin{array}{l}\text { meg } \\
0.005\end{array}$ & $\begin{array}{l}m e g \\
10\end{array}$ & $\begin{array}{l}m e g \\
0.2\end{array}$ \\
\hline $\begin{array}{l}\text { meter. } \\
\text { Ratio ohm- } \\
\text { meter. }\end{array}$ & $\begin{array}{l}\text { cranked. } \\
\text { Hand- } \\
\text { cranked. }\end{array}$ & $0-500$ & 10 & .05 & .010 & 50 & . \\
\hline $\begin{array}{l}\text { Simple ohm- } \\
\text { meter. }\end{array}$ & $\begin{array}{l}\text { Internal } \\
\text { battery. }\end{array}$ & 500 & 3 & .17 & .010 & 10 & .18 \\
\hline $\begin{array}{l}\text { Simple ohm- } \\
\text { meter. }\end{array}$ & $\begin{array}{l}\text { Internal } \\
\text { battery. }\end{array}$ & 500 & 2.5 & .20 & .010 & 10 & .2 \\
\hline $\begin{array}{l}\text { Ratio ohm- } \\
\text { meter. }\end{array}$ & $\begin{array}{l}\text { Hand- } \\
\text { cranked. }\end{array}$ & 500 & 5 & .10 & .010 & 50 & \\
\hline $\begin{array}{l}\text { Megohm } \\
\text { bridge. }\end{array}$ & $110 \vee \mathrm{a}-\mathrm{c}$ & 500 & 10 & & b. 001 & b 100 & \\
\hline
\end{tabular}

a Lowest and highest markings on scale exclusive of zero and "infinity" markings.

b At listed short-circuit current; additional ranges to $1,000,000 \mathrm{meg}$ at lower currents. other component parts must be accurate to better than 10 percent.

The data on the modified megohm bridge are included for reference. The instrument was found to be accurate to 1 percent and well suited for laboratory studies because of its wide voltage and resistance ranges. However, it would not be as convenient as the others for routine tests of installed floors.

\section{Electrostatic Tests}

The electrical tests of conductive flooring samples outlined in sections 4 and 5 have been made under deliberately varied conditions, such as relative humidity and applied voltage, to determine the effect of ambient conditions and of normal use upon the samples, and to evaluate the factors which may be expected to influence the measurements. To substantiate these results, additional experiments were carried out in which each type of floor was actually used as an intercoupler to reunite electrostatic charges. These experiments provided a direct test of the effectiveness of each type of floor in eliminating hazards from static electricity.

Tests in the NBS laboratories have shown that a person rising from a plastic-covered chair while wearing wool clothing causes a separation of charges at as high a time rate (and therefore charging current) as any human action tested. A comparatively low resistance is thus required to keep the voltage between the objects concerned (chair and person rising from it) below the minimum sparking voltage, about $400 \mathrm{v}$ in air at normal pressure. If the voltage is less than this, true electrostatic sparks do not occur [2]. This experiment therefore provides a good test of the actual performance of a floor, if the peak voltage between the objects can be measured.

A few measurements of the voltages produced in such tests have been made in the NBS laboratories by using a high-resistance voltage divider, cathode ray oscillograph, and camera. ${ }^{7}$ However, this proved to be too cumbersome for the many tests required for these floors, so that a simple peak-voltage indicator was constructed. It consisted of four small sensitive neon lamps (NE2 or equivalent) connected in series with a $40 \mu \mu \mathrm{f}$ capacitor across each. The lamps and capacitors were mounted in a small blackened metal tube having a lens at one end. The capacitors assure that equal transient (or alternating) voltages appear across each lamp until one lamp fires (glows), after which all glow. Tests showed that the firing voltage was about $300 \mathrm{v}$, somewhat less than the minimum sparking voltage. The "dark" resistance at lower voltages ranged from 5,000 to more than $20,000 \mathrm{meg}$. Additional tests were made later of some samples, with two neon lamps added to the indicator, so that the firing: voltage was about $450 \mathrm{v}$, approximately that of the standard instrument for measuring floors $(500 \mathrm{v})$.

For these tests a person wearing conductive shoes held the peak-voltage indicator. The other terminal

7 Since this is a transient voltage an ordinary electrostatic voltmeter can not be used. 
of the indicator was connected to the frame of a metal chair (having flat metal gliders $3 / 4$ in. diam) which rested on the flooring sample. ${ }^{8}$ The person sat in the chair, and then, while observing the indicator, rose from the chair (with a forward sliding motion) with his feet on the same sample and noted whether or not the lamps glowed. At least five such trials were made with each flooring sample. The resistance of the sample between two standard electrodes and between the metal frame of the chair and the subject was measured immediately after each test at three or five different locations on the sample.

Additional tests were made on an insulating floor with a resistor connected between the chair and the subject. The tests were repeated with resistors of successively lower value until the lamps glowed while the person rose from the chair. These tests thus determine the actual safe upper limit resistance for the motion and materials involved.

All of the tests with the flooring samples and the resistors were made at an ambient relative humidity of 20 percent, with a plastic covered chair and a subject who wore a wool suit, conditions which are very favorable to the generation of static electricity.

The results of these tests are given in table 8 . The last three rows of the table show that the actual safe limiting resistance to keep the voltage between the chair and subject below the minimum sparking voltage $(400 \mathrm{v})$ for the motion and materials used was about 30 megs. A resistance less than 20 to 30 megs was required to keep the voltage below $300 \mathrm{v}$, the firing voltage of the 4-lamp indicator.

The range of measured resistances between the chair and subject are given in the fourth column of the table. As indicated in section 5.4 this range is much greater with hard surfaced electrodes such as the leg tips on this chair than with resilient electrodes. (This is one reason why the resilient electrodes are preferred for routine tests.) The results show that except for sample No. 5 the peak voltage was less than $300 \mathrm{v}$ when the measured resistance between the chair and subject was less than about $30 \mathrm{meg}$, and vice versa. ${ }^{9}$ Thus there is excellent correlation between the resistance of a conductive floor as measured with a standard 500-v d-c instrument, and the resistance to the flow of electrostatic charges through the same electrodes (contacting objects).

The upper limit of resistance specified for a conductive floor with the standard electrode is $1 \mathrm{meg}$. The results show that, for all samples except Nos. 5 and 11 , the peak voltage is less than $300 \mathrm{v}$, if the resistance between the two standard electrodes is less than $1 \mathrm{meg}$, and vice versa. Thus the specified 1-meg limit with two standard electrodes is a reason-

8 Because of the small size of the sample only the front legs of the chair rested on the sample. Insulators were placed under the rear legs. For some of the tests with the $450-\mathrm{v}$ indicator, two flooring samples of the same type were connected together so that all four legs of the chair rested on the conductive floor.

together so that all four legs of the che manufacturer of sample No. 5 had applied a sealer which sometimes effectively insulated the hard-surface gliders of the a sealer which sometimes effectively insulated the hard-surface gliders of the
chair, but not the standard electrodes. With hard electrodes the breakdown chair, but not the standard electrodes. With hard electrodes the breakdown
voltage of this insulating film ranged from 100 to more than $400 \mathrm{v}$. This sealer is voltage of this insulating film ranged from 100 to more than $400 \mathrm{~V}$. This sealer
no longer applied on conductive floors by the manufacturer of this sample.
TABLE 8. Results of electrostatic tests

Ambient temperature $25^{\circ} \mathrm{C}$; relative humidity $20 \%$; plastic chair covering; wool garment (see text)

\begin{tabular}{|c|c|c|c|c|c|}
\hline \multirow{2}{*}{$\begin{array}{c}\text { Sample } \\
\text { No. }\end{array}$} & \multirow[b]{2}{*}{ Type } & \multicolumn{2}{|c|}{ Resistance (megs) between: } & \multicolumn{2}{|c|}{$\begin{array}{l}\text { Peak voltage } \\
\text { greater than: } a\end{array}$} \\
\hline & & $\begin{array}{c}\text { Two } \\
\text { standard } \\
\text { electrodes } \\
\text { (average) }\end{array}$ & $\begin{array}{c}\text { Chair and subject } \\
\text { (min. \& max.) }\end{array}$ & $300 \mathrm{~V}$ & $450 \mathrm{v}$ \\
\hline 2 & Ceramic.. & 0.2 & 0.3 to 0.5 & $\mathrm{No}_{\ldots}$ & \\
\hline 4 & Concrete & .9 & 3 to 30 & Yes... & No. \\
\hline 5 & Latex & .05 & 0.08 to 0.09 & Yes... & Yes. \\
\hline 6 & Linoleum. & .03 & & No $\ldots$ & \\
\hline 7 & Oxychloride & & 140 to 260 & Yes... & \\
\hline 8 & Oxychloride.. & 2 & 15 to 45 & Yes ... & No. \\
\hline 9 & Oxychloride & 30 & 200 to 400 & Yes... & \\
\hline 10 & Oxychloride & 1.5 & 7 to 65 & Yes... & No. \\
\hline 11 & Oxychloride & 0.3 & 1 to 50 & Yes $\ldots$ & Yes. \\
\hline 12 & Oxychloride... & .6 & 2 to 5 & $-\ldots$ & No. \\
\hline 13 & Rubber. & .1 & 0.08 to 0.18 & No $\ldots .$. & \\
\hline 15 & Vinyl .... & .2 & .3 to $0.4 \ldots$ & No & $-\ldots$ \\
\hline & Resistor $20 \mathrm{meg}$ & ... & - & No_... & \\
\hline- & Resistor $30 \mathrm{meg}$ & & & Yes $\ldots$ & No. \\
\hline & Resistor 50 meg & & & Yes... & Yes. \\
\hline
\end{tabular}

a "Yes" signifies that the designated peak voltage was exceeded at least once in five or more trials.

ably valid criterion of the performance of these floors.

These tests therefore show that the actual resistance between the objects on which the charges are generated (or transferred by induction) is the important criterion of the effectiveness of a conductive floor as an electrostatic intercoupler, and that this can be measured reasonably well with the specified 500-v instrument. In case of doubt, as for example floors which are slightly above the 1-meg limit with the standard electrodes, measurements of the resistance between objects in the room can provide additional evidence of the safety of the floor (and the contacting objects) with respect to the hazards from static electricity.

These tests indicate that for resilient floors there is an appreciable "factor of safety" (about 10) for the present 1-meg specification, even at this verylow relative humidity, because the resistance of such floors is relatively independent of the hardness of the contacting objects. There would appear to be no such factor for hard-surfaced floors. However, additional tests indicate that there is a very large factor of safety (10 or more) if, as specified in NFPA No. 56, materials such as wool and plastics are prohibited. Such materials are excellent electrostatic generators because of their very high electrical resistivities. In addition, because the resistance of many insulating materials depends upon the ambient relative humidity, there is another very large factor of safety if, as recently specified in NFPA No. 56, a relative humidity of 50 to 60 percent is maintained.

\section{Nonelectrical Properties}

\subsection{Indentation}

Indentation studies included the determination of initial indentation under load and residual indenta- 
tion after removal of the load. The initial indentation is sometimes referred to as the "comfort value", in that it expresses the ability of a floor to depress readily under foot. The value of the residual indentation, on the other hand, is an indication of the resistance to permanent deformation due to a concentrated load, such as a table leg. The ideal floor might thus be considered as one which has a high initial indentation or "give" and a low residual indentation or high recovery. In table 9, linoleum, rubber, and vinyl show a much higher initial indentation than the ceramic, concrete, and oxychloride materials. However, other important factors are involved in determining comfort value which are of an indirect nature, but which can be of major importance, e.g., the type of footwear involved. Comparison of these results with those reported in BMS-73 [7] show that the indentation characteristics of the conductive materials are comparable to those of the corresponding nonconductive materials.

TABLE 9. Indentation characteristics

\begin{tabular}{|c|c|c|c|c|c|c|c|c|c|}
\hline \multirow{3}{*}{$\begin{array}{l}\text { Sam- } \\
\text { ple } \\
\text { No. }\end{array}$} & \multirow{3}{*}{ Type } & \multirow{3}{*}{$\begin{array}{c}\text { Thick- } \\
\text { ness }\end{array}$} & \multicolumn{3}{|c|}{ Initial indentation } & \multicolumn{4}{|c|}{ Residual indentation } \\
\hline & & & \multirow{2}{*}{ A } & \multirow{2}{*}{ B } & \multirow{2}{*}{$\mathrm{C}$} & \multicolumn{3}{|c|}{$\begin{array}{c}1 \mathrm{hr} \text { after removal } \\
\text { of load }\end{array}$} & \multirow{2}{*}{$\begin{array}{c}\begin{array}{c}48 \mathrm{hr} \\
\text { after } \\
\text { rem ova } \\
\text { of load }\end{array} \\
\text { C }\end{array}$} \\
\hline & & & & & & A & B & C & \\
\hline & Cer & $\begin{array}{l}\text { in. } \\
0.25\end{array}$ & $\begin{array}{l}\text { in. } \\
0.000\end{array}$ & $\begin{aligned} & \text { in. } \\
& 0.000\end{aligned}$ & $\begin{array}{l}\text { in. } \\
0.000\end{array}$ & in. & in. & in. & in. \\
\hline $\begin{array}{l}2 \\
3\end{array}$ & & .25 & .000 & .000 & .000 & & & & \\
\hline $\begin{array}{l}3 \\
4\end{array}$ & $\begin{array}{l}\text { Coatin } \\
\text { Conere }\end{array}$ & $\begin{array}{l}.035 \\
50\end{array}$ & .011 & .007 & .009 & 0.003 & 0.000 & 0.000 & \\
\hline 5 & Late: & .443 & .009 & .007 & .014 & .002 & .000 & .000 & \\
\hline 6 & Linoleum & .134 & .024 & .005 & .007 & .003 & .000 & .002 & 0.001 \\
\hline 7 & Oxye & .50 & .000 & .000 & .000 & & & & \\
\hline $\begin{array}{l}8 \\
9\end{array}$ & $-\mathrm{d}$ & .50 & .00 & .000 & .000 & & & & \\
\hline 10 & $\mathrm{~d}$ & .50 & .000 & .000 & .000 & & & & \\
\hline 11 & do & .50 & .0 & .000 & .0 & & & & \\
\hline 12 & & & .002 & & .000 & .000 & & & \\
\hline 13 & $\mathrm{R}$ & .126 & .029 & .008 & .006 & .002 & .000 & .0 & .000 \\
\hline 14 & Viny & .12 & .043 & .021 & .024 & .06 & .00 & .0 & .0 \\
\hline 15 & - do & .193 & .047 & .011 & .017 & .002 & .002 & .009 & .006 \\
\hline
\end{tabular}

$\mathrm{A}=80$-lb load applied $10 \mathrm{~min}$ through a 0.178 -in.-diam indenter foot $(3,200$ $1 \mathrm{~b} / \mathrm{in}^{2}{ }^{2}$.

$\mathrm{B}=100-1 \mathrm{~b}$ load applied $10 \mathrm{~min}$ through a 1.125 -in.-diam indenter foot (100 $1 \mathrm{~b} / \mathrm{in}^{2}{ }^{2}$.

$\mathrm{C}=100-1 \mathrm{~b}$ load applied 7 days through a 1.125-in.-diam indenter foot $(100$ $\mathrm{lb} /$ in. $^{2}$.

In the case of sample No. 3 (coating), the results reflected predominantly the indentation characteristics of the plywood backing, because of the thinness of the coating material. The result would undoubtedly have been different if the same material had been applied over concrete.

The indentation tester and procedure used in making the indentation and recovery determinations are described in detail in Report BMS-73 [7] and in Federal Specification LLL-L-367 for Linoleum.

\subsection{Scratch Resistance}

Precise measurements of scratch resistance, as described in the paragraph below, were made on each sample. This value relates to the ease with which the floor surface can be scuffed and marred by abrasive material carried on shoes. Resistance of conductive flooring materials to surface scratching is of prime importance in operating rooms for the sake of cleanliness as well as the possible effect on electrical contact resistance. In order to establish a basis by which these values can be related to actual service, each sample was placed on the pedestrian traffic test ramp described later.

The Taber Scratch Tester was adapted to measure the scratch width of a diamond point at loads of $250,500,750$, and $1,000 \mathrm{~g}$. A level plate capable of travel at a uniform rate of $1 \mathrm{ft} / \mathrm{min}$ was used in moving the flooring sample under the diamondpoint scratch tool. A scratch 2 in. long was made and the width of the scratch was measured at three locations with a $20 \times$ Brinell microscope containing a scale graduated in $0.1 \mathrm{~mm}$. The average of the three measurements was converted to the nearest 0.001 in. and recorded as scratch width in mils. The graph, figure 7 , illustrates the results.

A pedestrian traffic test ramp was constructed (see fig. 8). Each flooring sample was securely placed on the test ramp and a photoelectric counter was installed to count passages over the ramp. The length of the entrance at each end of the test ramp was altered every 3 months, causing a change in the foot traffic pattern and therefore insuring that each sample received the same amount of wear. The ramp was located on the third floor of the Industrial Building, NBS, away from street grit, gravel, and water, but exposed to light industrial-type dirt and dust. No attempt was made to maintain the samples other than an occasional dry sweeping. These conditions were considered more severe than in hospital operating rooms, resulting in an accelerated test. Photographs taken after 11 months of wear $(100,000$ passages) were compared with photographs of unexposed flooring to determine the extent of scratching, smudging, and other damage (see fig. 9). A comparison chart of visual appearance of the scratching on the exposed samples is listed below the graph in figure 7.

\subsection{Slipperiness}

Tests of relative slipperiness of the conductive flooring samples were made with leather and rubber heels under both wet and dry conditions. The method of testing and a description of the instrument used have been previously reported [8]. Slipperiness is not a constant of the walkway surface or of the contact surface of the footwear alone, but is a function of both surfaces and is materially affected by their conditions. Therefore, an unqualified evaluation of a particular floor or floor finish may be very misleading.

The results in table 10 show the antislip coefficients; the higher the value, the less slippery the surface. Comparison of these results show that the antislip characteristics of the conductive materials are comparable to those of the corresponding nonconductive materials. 


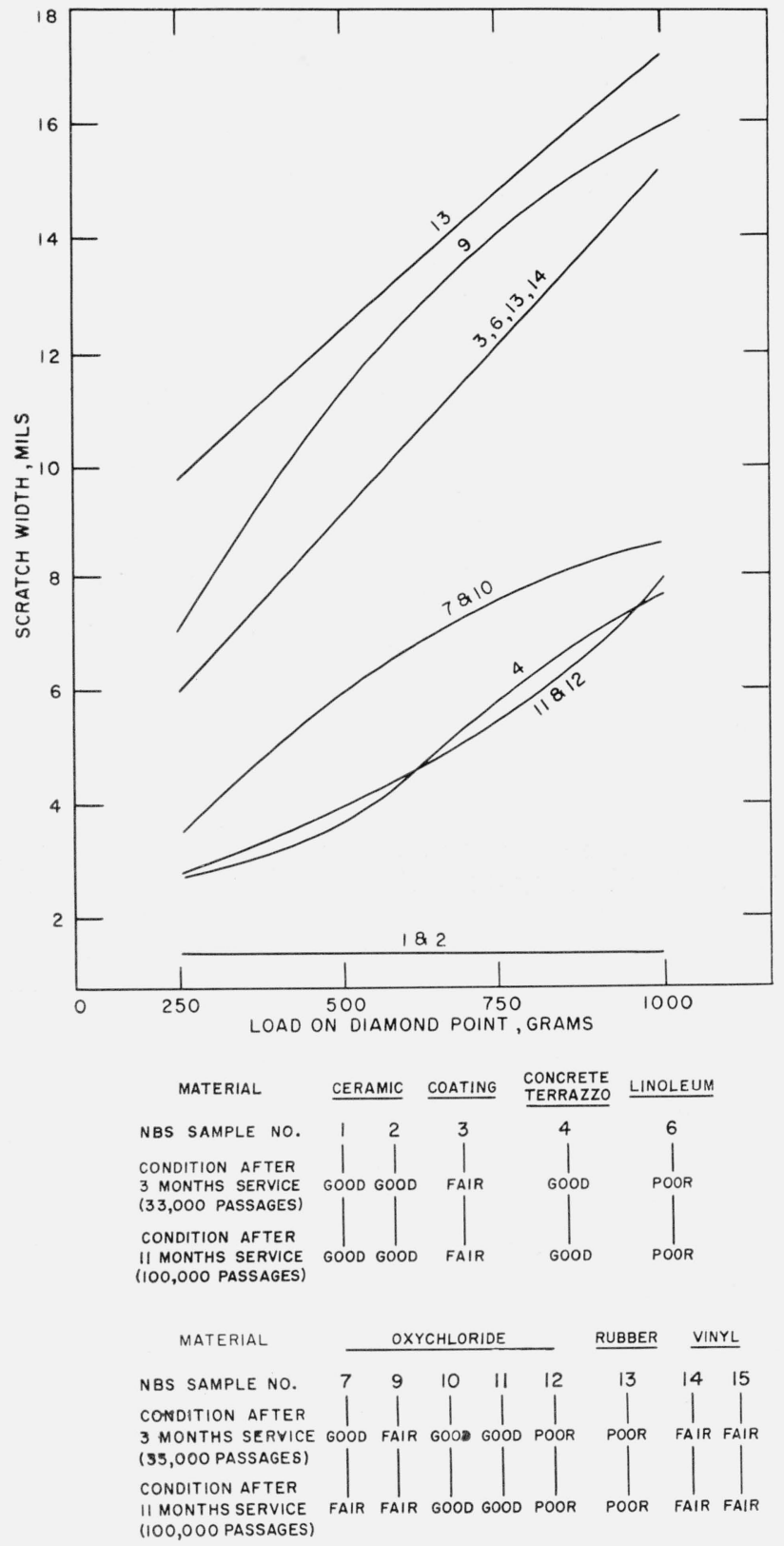

Figure 7. Resistance to scratching.

\subsection{Scrubbing}

The durability of permanent type conductive floorings is quite difficult to assess and no suitable short-term evaluation tests were available. The drytraffic tests discussed in section 7.2 and the stainresistance tests in section 7.6 were made in an attempt to judge the relative serviceability of these materials for operating room floors. In addition, because of the frequent washing and cleaning of operating room floors, an apparatus was designed to produce a continuously agitated washing effect. The samples were placed on a plate which rotated

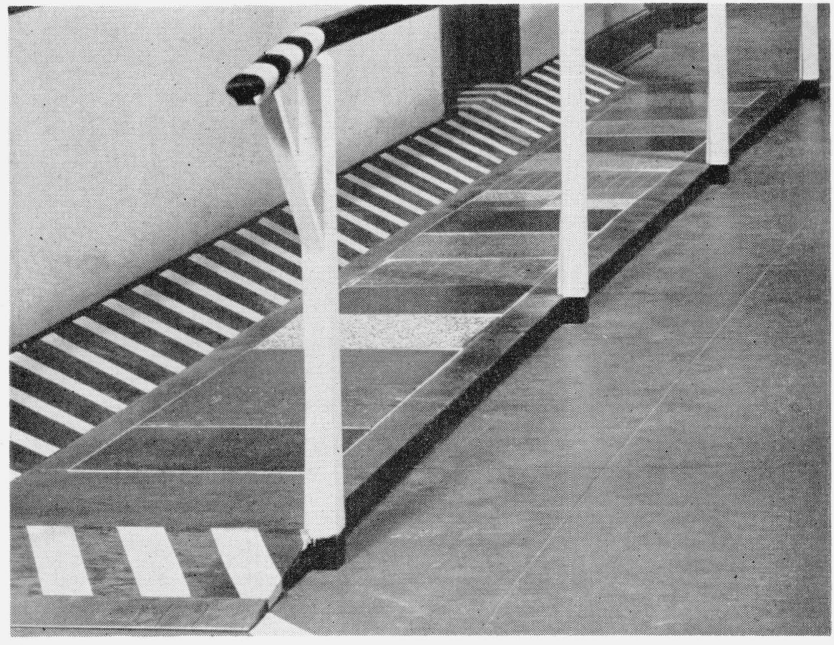

Figure 8. View of pedestrian traffic test ramp.

Each sample was 18 in. by 18 in.

at $4 \mathrm{rph}$ and the surface of each sample was kept continuously wet. A brush was used as the scrubber and was rotated at $180 \mathrm{rpm}$ under a total load of $500 \mathrm{~g}$. Each sample was exposed to this continuous wet-brushing action for $52 \mathrm{hr}$. The samples were examined visually by comparing the exposed with the nonexposed areas, and by electrical conductivity measurements.

Except for one of the oxychlorides the samples were not significantly affected by this severe scrubbing test. Sample No. 8 showed a large amount of wear and erosion, so that the end effect was a removal of the conductive matrix below the level of the nonconductive chips. The electrical resistance of this sample increased to two megohms. In addition, samples No. 9, 10, and 11 showed a slight amount of erosion and pitting, but their electrical conductivity was not affected.

TABLE 10. Relative slipperiness

\begin{tabular}{|c|c|c|c|c|c|}
\hline \multirow{3}{*}{$\begin{array}{c}\text { Sample } \\
\text { No. }\end{array}$} & \multirow{3}{*}{ Type } & \multicolumn{4}{|c|}{ Antislip coefficient } \\
\hline & & \multicolumn{2}{|c|}{ Leather heel } & \multicolumn{2}{|c|}{ Rubber heel } \\
\hline & & Dry & Wet & Dry & Wet \\
\hline $\begin{array}{l}1 \\
2 \\
3 \\
4 \\
5\end{array}$ & $\begin{array}{l}\text { Ceramic } \\
\text { Ceramic-and } \\
\text { Coating- } \\
\text { Concrete terrazzo- } \\
\text { Latex terrazzo }\end{array}$ & $\begin{array}{l}0.37 \\
.34 \\
.33 \\
.43 \\
.32\end{array}$ & $\begin{array}{l}0.26 \\
.26 \\
.26 \\
.26 \\
.10\end{array}$ & $\begin{array}{r}0.68 \\
.72 \\
.74 \\
.56 \\
.73\end{array}$ & $\begin{array}{l}0.44 \\
.31 \\
.46 \\
.30 \\
.13\end{array}$ \\
\hline $\begin{array}{r}6 \\
7 \\
8 \\
9 \\
10\end{array}$ & $\begin{array}{l}\text { Lincleum } \\
\text { Oxychloride- } \\
\text { Oxychloride-- } \\
\text { Oxychloride-- } \\
\text { Oxychloride }\end{array}$ & $\begin{array}{l}.37 \\
.39 \\
.36 \\
.21 \\
.37\end{array}$ & $\begin{array}{l}.18 \\
.38 \\
.15 \\
.18 \\
.14\end{array}$ & $\begin{array}{l}.68 \\
.68 \\
.62 \\
.58 \\
.58\end{array}$ & $\begin{array}{l}.37 \\
.48 \\
.21 \\
.24 \\
.22\end{array}$ \\
\hline $\begin{array}{l}11 \\
12 \\
13 \\
14 \\
15\end{array}$ & $\begin{array}{l}\text { Oxychloride } \\
\text { Oxychloride- } \\
\text { Rubber } \\
\text { Vinyl- } \\
\text { Vinyl }\end{array}$ & $\begin{array}{l}.37 \\
.34 \\
.39 \\
.26 \\
.28\end{array}$ & $\begin{array}{l}.12 \\
.13 \\
.12 \\
.16 \\
.13\end{array}$ & $\begin{array}{l}.55 \\
.54 \\
.67 \\
.46 \\
.63\end{array}$ & $\begin{array}{l}.16 \\
.39 \\
.13 \\
.10 \\
.23\end{array}$ \\
\hline
\end{tabular}



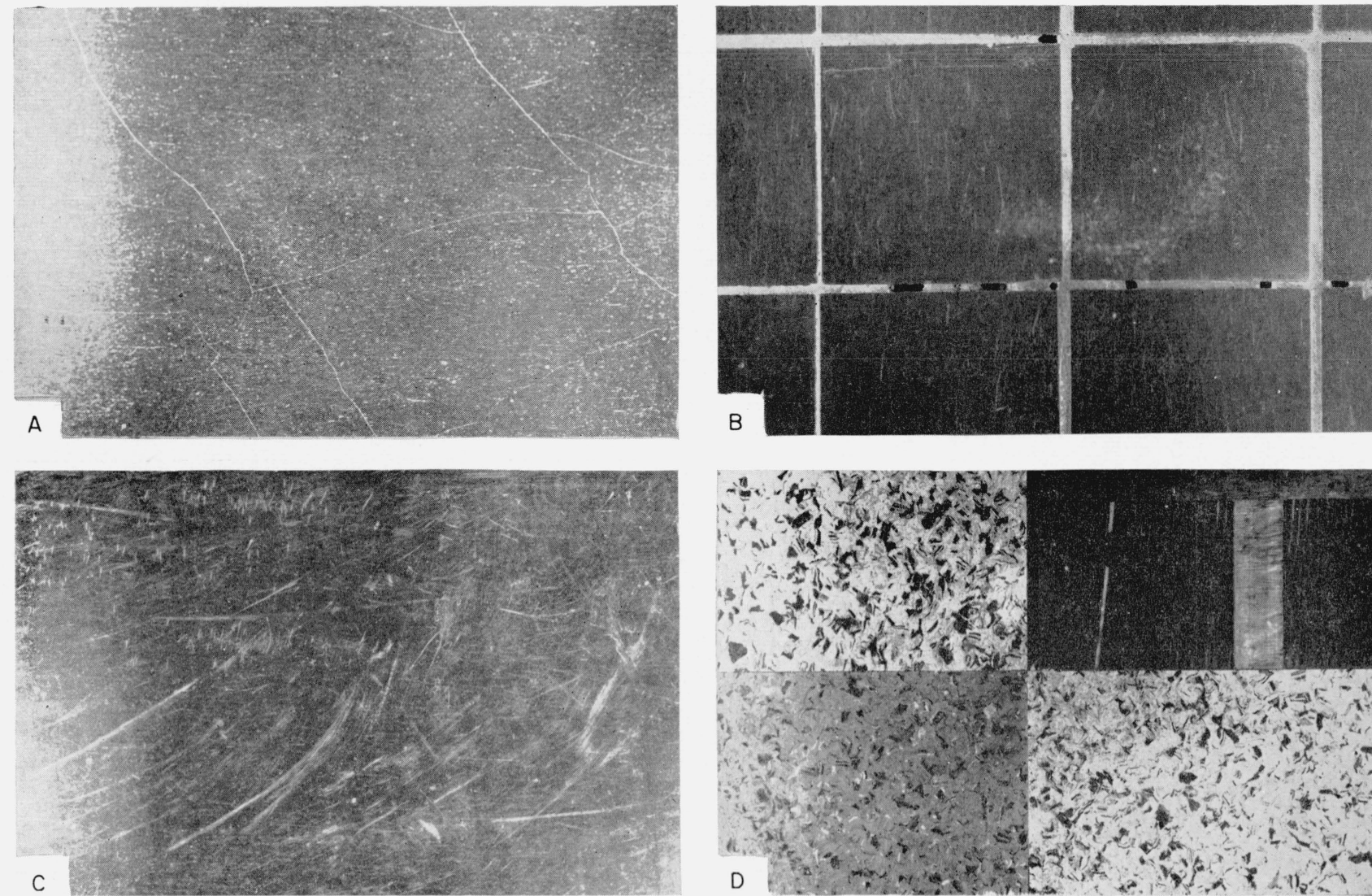

FIGURE 9. Photographs of four samples from the pedestrian traffic test ramp which were appreciably affected by the test.

A, Sample No. 8 (oxychloride), showing hairline cracks; B, Sample No. 2 (ceramic), showing pitting in mortar joints; C, Sample No. 13 (rubber), showing extreme scuffing and scratching. No wax was used; D, Sample No. 15 (vinyl), showing extreme soiling of light colored tiles. One tile has been removed to show the copper

\subsection{Water Absorption}

It has been considered desirable that a flooring material designated for an area subject to frequent washing should have a very low rate of water absorption in order to reduce staining, leaching, and erosion by water and detergents. To establish the rates of water absorption the following test was performed on each sample:

One-tenth milliliter of water was placed on the sample with a pipet and covered with a watch glass. The number of minutes required for complete absorption of the $0.1 \mathrm{ml}$ of water was taken as the time of absorption. Complete absorption was assumed to have taken place when light no longer was reflected from the wetted surface of the sample. All the flooring materials except the five listed below required more than $5 \mathrm{hr}$ for the water to disappear and can therefore be considered fairly impervious to water.

\begin{tabular}{|c|c|c|}
\hline No. & Type & $\begin{array}{c}\text { Time of absorp- } \\
\text { tion }\end{array}$ \\
\hline $\begin{array}{r}4 \\
8 \\
9 \\
10 \\
11\end{array}$ & $\begin{array}{l}\text { Concrete terrazzo } \\
\text { Oxy chloride } \\
\text { Oxy chloride } \ldots \\
\text { Oxychloride } \ldots \\
\text { Oxychloride } \ldots\end{array}$ & $\begin{array}{r}\min \\
15 \\
4 \\
6 \\
6 \\
22\end{array}$ \\
\hline
\end{tabular}

\subsection{Stain Resistance}

A high resistance to staining (or ease of cleaning when stained) is a desirable characteristic of a flooring material intended for use in an area where there is likely to be spillage. Table 11 lists recommended methods for removing certain stains. Care should be used in applying the solutions. For example, acid solutions are usually the most effective means of removing rust stains from concrete; 10 percent solutions of hydrochloric or phosphoric acid are commonly used. Acids should not, however, be allowed to remain in contact with the surface any longer than is necessary to remove the stains. With any such treatment, some roughening of the concrete is inevitable and may be conspicuous. As a precaution it is advisable to carry out a trial on a small area to determine if the resulting appearance is acceptable. Table 12 gives results of tests carried out to determine the effect on the conductive floor samples of various staining agents and the ease or difficulty with which the stains were removed.

\section{Summary and Conclusions}

1. The conductive floors tested should give satisfactory service in hospital operating suites, with the reservations outlined below. Similar conclusions can be drawn from the results of extensive tests by the staff of the National Research Council of Canada of several types of installed floors [9]. 
TABLE 11. Stain-removal methods

\begin{tabular}{|c|c|c|c|c|c|c|c|}
\hline Stain & Linoleum & Ceramic & Concreteterrazzo & Oxychloride & Vinyl & Coating & Rubber \\
\hline Blood............ & \multicolumn{7}{|c|}{ Apply cool water and rub with cloth. If stain persists, dampen cloth with ammonia. } \\
\hline Grease or oil_........- & $\begin{array}{l}\text { Apply detergent } \\
\text { and rub with } \\
\text { cloth. }\end{array}$ & \multicolumn{3}{|c|}{$\begin{array}{l}\text { Apply detergent and rub with cloth. If stain persists apply kerosene or } \\
\text { varsol on spot, permit to soak, wipe dry and wash with detergent, or mix } \\
\text { kerosene or varsol with fuller's earth to form paste. Apply paste to spot } \\
\text { and let stand for several hours. Repeat if necessary. }\end{array}$} & \multicolumn{3}{|c|}{ Apply detergent and rub with cloth. } \\
\hline $\begin{array}{l}\text { Ink (washable, } \\
\text { writing, and } \\
\text { drawing). }\end{array}$ & \multicolumn{7}{|c|}{$\begin{array}{l}\text { Apply detergent and rub with cloth. If stain persists, mix } 1 \text { part sodium perborate to } 25 \text { parts water. Mix with whiting (calcium carbonate) } \\
\text { to form paste. Apply paste to spot and leave until dry. }\end{array}$} \\
\hline Paint or enamel..... & \multicolumn{4}{|c|}{$\begin{array}{l}\text { Remove excess with putty knife and/or No. } 0 \text { steel wool. } \\
\text { detergent. }\end{array}$} & Wash with & \multicolumn{2}{|c|}{$\begin{array}{l}\text { Remove with putty knife } \\
\text { and No. } 0 \text { steel wool. }\end{array}$} \\
\hline Iodine...- & \multicolumn{2}{|c|}{ Apply alcohol and rub with cloth---- } & \multicolumn{2}{|c|}{ Apply alcohol and cover with fuller's earth... } & \multicolumn{3}{|c|}{ Same as for linoleum. } \\
\hline Rust...-- & $\begin{array}{l}\text { Rub with No. } 0 \\
\text { steel wool and } \\
\text { wash with de- } \\
\text { tergent. }\end{array}$ & $\begin{array}{l}\text { Apply water and } \\
\text { apply solution o } \\
\text { Let remain ur } \\
\text { water. }\end{array}$ & $\begin{array}{l}\text { d rub with cloth. If stain persists } \\
\text { of } 1 \text { part oxalic acid to } 9 \text { parts water. } \\
\text { ntil dry. Wash thoroughly with }\end{array}$ & $\begin{array}{l}\text { Apply water and } \\
\text { rub with cloth. } \\
\text { If stain persists, } \\
\text { dissolve 1 part } \\
\text { sodium citrate in } \\
6 \text { parts water. } \\
\text { Make a paste } \\
\text { with whiting (cal- } \\
\text { cium carbonate) } \\
\text { and apply to } \\
\text { stain, or wash } \\
\text { with sodium ci- } \\
\text { trate solution and } \\
\text { add pad of cotton } \\
\text { soaked in sodium } \\
\text { bisulfite. Wash } \\
\text { thoroughly with } \\
\text { water. }\end{array}$ & Same as for li & aoleum. & \\
\hline
\end{tabular}

Sole and heel mark-

Apply detergent and rub with cloth.

TABLE 12. Results on removal of stains

\begin{tabular}{|c|c|c|c|c|c|c|c|c|}
\hline $\begin{array}{c}\text { Sample } \\
\text { No. }\end{array}$ & Type & Blood & $\begin{array}{l}\text { Grease } \\
\text { or oil }\end{array}$ & Ink & $\begin{array}{l}\text { Paint } \\
\text { or } \\
\text { enamel }\end{array}$ & Iodine & Rust & $\begin{array}{c}\text { Sole } \\
\text { and } \\
\text { heel } \\
\text { marks }\end{array}$ \\
\hline & \multirow{7}{*}{$\begin{array}{l}\text { Ceramic a } \\
\text { Ceramic a } \\
\text { Coating } \\
\text { Concrete ter- } \\
\text { razzo- } \\
\text { Latex terrazzo } \\
\text { with sealer } \\
\text { Latex terrazzo } \\
\text { without sealer }\end{array}$} & B & B & B & B & B & B & A \\
\hline & & B & B & B & B & B & B & $\mathrm{A}$ \\
\hline & & B & B & B & B & B & B & B \\
\hline & & B & $\mathrm{C}$ & $\mathrm{C}$ & B & B & $\mathrm{C}$ & B \\
\hline & & P & $\mathrm{R}$ & $P$ & $\mathrm{P}$ & $\mathrm{B}$ & $B$ & $\mathrm{P}$ \\
\hline \multirow{2}{*}{5} & & B & B & B & $\mathrm{B}$ & B & B & $\mathrm{B}$ \\
\hline & & B & B & C & B & F & C & B \\
\hline & Linoleum & B & B & B & B & B & B & A \\
\hline & 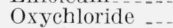 & D & B & D & B & B & & B \\
\hline & Ox & $\mathrm{F}$ & $\mathrm{F}$ & $\mathrm{F}$ & B & B & B & \\
\hline & Oxychlo & B & $\mathrm{F}$ & D & B & A & $\mathrm{F}$ & B \\
\hline & Oxychloric & B & B & D & B & $\mathrm{F}$ & B & A \\
\hline & Oxychloride & D & $\mathrm{F}$ & D & B & B & B & B \\
\hline & $\mathrm{Ru}$ & B & B & B & B & B & C & B \\
\hline & Viny & B & B & B & B & C & B & C \\
\hline & Vinyl.. & B & B & C & B & $\mathrm{C}$ & B & C \\
\hline
\end{tabular}

Note: A, Staining material would not stain or mark floor; B, stain completely removed with little effort; C, stain completely removed, but with difficulty $\mathrm{D}$, stain completely removed, but floor surface bleached or etched; F, stain not removed.

a Results on cement joints same as No. 4, concrete terrazzo.

2. In general, any particular type of conductive flooring may be expected to render service comparable to nonconductive flooring of the same type. Consequently, an architect may base his choice of a conductive flooring material on his knowledge of the behavior of similar nonconductive materials, with the following limitations:

(a) The durability and appearance of at least two of the available materials (linoleum and rubber) may depend on periodic waxing. Conductive waxes containing carbon black which do not deposit an insulating film are available and should be esthetically as well as electrically satisfactory on these uniformly black floors. Sealers should not be used on conductive floors until proven satisfactory by extensive electrical tests.

(b) Since the most commonly used conductive medium (acetylene black) is black, the colors available in most types of conductive floors are limited. However, terrazzo and other pattern effects can be used. Detailed descriptions of some of the available colors and patterns are given in section 3 .

(c) The electrical resistance of the oxychloride floors depended on their moisture content, which in turn was governed by the humidity of the air and by water added during washing. The results of the tests given in this report indicate that if this material is used the relative humidity of the air in the room in which it is installed should be controlled and the cleaning schedule for the floor should be carefully established and maintained. The laboratory tests indicate that otherwise the electrical resistance of the floor may fall outside the accepted limits.

3. The results of this investigation indicate that the presently accepted method of measuring the resistance of installed floors, described in NFPA No. 56, reasonably simulates the conditions under which a floor is expected to function as an electrostatic intercoupler. 
4. The results also show that current specifications and methods of measuring the physical properties of nonconductive floorings are satisfactory for conductive floorings.

The work described in this report was done under a project sponsored jointly by the Office of the Chief of Engineers, Department of the Army; Bureau of Yards and Docks, Department of the Navy; and Engineering Division, Director of Civil Engineering, Department of the Air Force.

The authors appreciate the cooperation of the staff of the Division of Building Research of the National Research Council of Canada, particularly Mr. P. J. Sereda, in making available their experience with conductive flooring. The cooperation of the numerous manufacturers who generously provided samples is also acknowledged.

\section{References}

[1] P. G. Guest, V. W. Sikora, and B. Lewis, Static electricity in hospital operating suites: Direct and related hazards and pertinent remedies, Bureau of Mines Report of Investigation 4833, 64 pp. (1952).

[2] F. B. Silsbee, Static electricity, NBS Circ. 438 (June 1942).

[3] F. L. Hermach, Hazards from static electricity, The Military Engineer 44, 287 (1952).

[4] Recommended safe practice for hospital operating rooms, N.F.P.A. No. 56, National Fire Protection Association (reproduced in part in appendix A of this report).

[5] Robin Beach, Electrostatic safety for hospital operating rooms, Elec. Eng. 72, 329 (April 1953).

[6] AIEE master test code for resistance measurements, Publication No. 550, Am. Inst. Elec. Engrs., New York, N.Y.

[7] Percy A. Sigler and Myrtle B. Woodward, Indentation of floor coverings, NBS BMS Report 73, 7 pp. (1941).

[8] Percy A. Sigler, Martin N. Geib, and Thomas H. Boone, Measurement of the slipperiness of walkway surfaces, J. Research NBS 40, 5, 339 (May 1948).

[9] P. J. Sereda, Properties of commercial conductive flooring for hospital operating rooms, Division of Building Research, Nat. Research Council Can., NRC 4031.

10. Appendix A. Excerpts ${ }^{10}$ from the 1958 Edition of NFPA Publication No. 56, Recommended Safe Practice for Hospital Operating Rooms

\section{6-2. Conductive Flooring.}

(a) Resistance.

1. To prevent the accumulation of dangerous electrostatic charges, the surface of the floor shall provide a path of moderate electrical conductivity between all persons and equipment making contact with the floor. No point on a non-conductive element in the surface of the floor shall be more than $1 / 4$ inch from a conductive element of the surface.

NOTE: It is not necessary to provide a special floor-to-ground connection unless required by the authority having jurisdiction.

2. The resistance of the conductive floor shall be

${ }^{10}$ Reproduced by permission of the National Fire Protection Association, 60 Batterymarch Street, Boston, Massachusetts. less than 1,000,000 ohms as measured between two electrodes placed three feet apart at any points on the floor.

3. For additional protection against electric shock, the resistance of the floor shall be more than 25,000 ohms, as measured between a ground connection and an electrode placed at any point on the floor, and also as measured between two electrodes placed 3 feet apart at any points on the floor.

\section{(b) Method of Test.}

1. The floor shall be clean and dry and the room shall be free of explosive gas mixtures. Each electrode shall weigh 5 pounds and shall have a dry, flat, circular contact area $2 \frac{1}{2}$ inches in diameter which shall comprise a surface of aluminum or tin foil 0.0005 to 0.001 inch thick backed by a layer of rubber $1 / 4$ inch thick and measuring 50 plus or minus 10 hardness as determined with a Shore Type A durometer. (American Society for Testing Materials Tentative Method of Test for Indentation of Rubber by Means of a Durometer, ASTM Designation D676-49'T, obtainable from ASTM, 1916 Race St., Philadelphia 3, Pa.)

2. A suitably calibrated ohmmeter with a nominal open-circuit output voltage of 500 volts D.C. and a short-circuit current of 2.5 to 10 milliamperes shall be used. Measurements* shall be made at five or more locations in each room and the results averaged. For compliance with Section 6-2(a)2, the average shall be within the limits specified and no value shall be greater than 5 megohms. For compliance with Section 6-2(a)3, no location shall have a resistance of less than $10,000 \mathrm{ohms}$ and the average for not less than five locations shall be greater than 25,000 ohms. Where resistance to ground is measured, two measurements shall be made at each location, with the test leads interchanged at the instrument between measurements, with the average to be taken as the resistance to ground at that location. All readings may be taken with the electrode or electrodes more than $3 \mathrm{ft}$. from any ground connection or grounded object resting on the floor.

*NOTE: If the resistance changes appreciably with time during a measurement, the value observed after the voltage has been applied for about 5 seconds shall be considered to be the measured value.

\section{3-10. Testing and Maintenance}

\section{(a) Conductive Floors}

1. The resistance of conductive floors shall be initially tested prior to use, by the method described in Section 6. Thereafter measurements shall be taken at intervals of not more than one month. A permanent record of the readings shall be kept.

2 . To be effective the surface of conductive floors shall not be insulated by a film of oil or wax. Any waxes, polishes, or dressings used for maintenance of conductive floors shall not adversely affect the resistance of the floor. 
3. Cleaning procedures for conductive floors shall be established, then carefully followed to assure that conductivity characteristics of the floors are not adversely affected by such treatment.

\section{A-6-2. Conductive Flooring}

In hazardous locations, a conductive floor serves as a convenient means of electrically connecting persons and objects together to prevent the accumulation of electrostatic charges. A resistance not exceeding 5 to 10 megohms between the objects or persons is generally sufficient to prevent dangerous voltages. The upper limit of 1,000,000 ohms for the resistance of the floor has been chosen as meeting this requirement with a reasonable factor of safety and with reasonable provision for other resistances in the conductive path.

The conductive floor produces a definite shock hazard in the absence of an isolated electrical system. The isolating transformers must always be installed simultaneously with or prior to the installation of the conductive floor. Installation in the opposite sequence is definitely dangerous and should not be contemplated.

The resistance of some flooring materials increases with age. Floors of such materials should have an initial resistance low enough to permit increases in resistance with age without exceeding the limits prescribed in Section 6-2(a)2.

A conductive floor need not be provided with a special grounding connection to prevent the accumulation of charges due to the motion of objects or persons resting on it. To be effective it is necessary only that it be conductive and that the persons and objects be electrically connected to it. Considerable conductivity to ground is generally attained in the usual construction, often because of the proximity of grounded conduits and water pipes. This incidental conductivity to ground and the large area, and therefore capacitance of the floor, make any hazard due to the entry of charged persons or objects into the protected zone negligible, provided such persons and objects have proper conductivity to the floor. Grounded objects within the room, such as portable electrical equipment, will be electrically connected to the floor by the requirements of Section 6 , and will thus ground the floor, so that such objects do not increase this electrostatic hazard. Therefore, a special grounding connection need not be incorporated in the floor for electrostatic protection, unless desired or otherwise required.

\section{Appendix B. Four-Terminal Method of Measuring Contact and Internal Resistivities}

If rectangular current electrodes, $\mathrm{C}_{1}$ and $\mathrm{C}_{2}$, and very narrow potential electrodes, $\mathrm{P}_{1}$ and $\mathrm{P}_{2}$, are placed parallel to each other on the same surface of a rectangular specimen of uniform internal or volume resistivity, $r$, as shown in figure 5, all equipotential lines are also parallel to the electrodes. Then, if $V, E$, and the total resistance, $R$, are measured, we have $I=V / R=E / Q=E l b / r f$ where $Q$ is the resistance between $P_{1}$ and $P_{2}$. Thus $r=E R l b / V f$ (in ohm-cm if $R$ is in ohms and all dimensions are in centimeters).

The contact resistivity, $s$, may be defined as the resistance of a unit area of the interface between the current electrodes and samples. If the internal resistance of the sample under each current electrode is neglected, ${ }^{11}$ we may compute the internal resistance, $T$, of the sample to be approximately $T=r d / l b=$ $E R d / V f$. The contact resistance under one electrode is $S=s / w l$ where $w l$ is the apparent contact area of the electrode. Since, under these simplifying assumptions, $R=T+2 S=T+2 s / w l$, we have in ohm-cm ${ }^{2}$

$$
s=\frac{w l R}{2}\left(1-\frac{E d}{V f}\right) \text {. }
$$

\section{Appendix C. Calculation of Resistance From Contact and Internal Resistivities}

The resistance between two NFPA electrodes of diameter $d$ spaced $D$ centimeters apart $(D>>d)$ on a large floor may be evaluated by adding together the contact resistance under both electrodes and the internal resistance of the floor between two imaginary cylinders which form the downward projections of the electrodes through the floor (again neglecting the resistance of the material under the electrodes). ${ }^{11}$ The internal resistance may be calculated by using established formulas of the capacitance per unit length between two long cylinders of the same diameter and spacing, and applying a conversion formula to find the internal resistance $T$. In $\operatorname{cgs}$ electrostatic units this capacitance, for a length $b$ (corresponding to the thickness of the floor), is

$$
C=\frac{b}{4 \ln \frac{2 D}{d}},
$$

where $\ln$ is the natural logarithm.

The conversion formula from which the internal resistance can be computed can be expressed as $T=r / 4 \pi C . \quad$ Thus

$$
T=\frac{r}{\pi b} \ln \frac{2 D}{d} .
$$

The sum of the contact resistances for both electrodes is $2 S=8 s / \pi d^{2}$ and the total resistance between electrodes is approximately

$$
R=\frac{2.5 s}{d^{2}}+\frac{0.7 r}{b} \log \frac{2 D}{d},
$$

where $\log$ signifies the logarithm to the base 10 .

The above relations presuppose a uniform material having a negligible voltage coefficient of resistance. Thus, they are only approximate.

11 Approximate mathematical investigation shows that because of the high ratio of contact to internal resistivity of these flooring materials, the error introratio of contact to internal resistivity of these flooring materials, the error intro-
duced by this assumption is much smaller than the influence of other factors, such as the nonuniformity and the voltage coefficient of resistivity.

Washington, D.C.

(Paper 63C2-16) 